\title{
Wastewater-based epidemiology predicts COVID-19 community prevalence
}

\section{Blythe Layton}

Clean Water Services

Devrim Kaya

Oregon State University https://orcid.org/0000-0002-7115-0845

Christine Kelly

Oregon State University

Kenneth Williamson

Clean Water Services

Silke Bachhuber

Oregon State University

Peter Banwarth

Benton County Health Department

Jeffrey Bethel

Oregon State University

Katherine Carter

Oregon State University

Benjamin Dalziel

Oregon State University https://orcid.org/0000-0002-9674-2783

\section{Mark Dasenko}

Oregon State University

\section{Matthew Geniza}

Oregon State University https://orcid.org/0000-0003-4828-7891

\section{Dana Gibbon}

Oregon State University

\section{Anne-Marie Girard}

Oregon State University

\section{Roy Haggerty}

Oregon State University

Kathryn Higley

Oregon State University

\section{Denise Hynes}

Oregon State University Jane Lubchenco 
Oregon State University https://orcid.org/0000-0003-3540-5879

\section{Katherine McLaughlin}

Oregon State University

\section{F. Javier Nieto}

Oregon State University

\section{Aslan Noakes}

Oregon State University

\section{Matthew Peterson}

Oregon State University

\section{Adriana Piemonti}

Clean Water Services

Justin Sanders

Oregon State University

\section{Brett Tyler}

Oregon State University https://orcid.org/0000-0003-1549-2987

Tyler Radniecki ( $\square$ tyler.radniecki@oregonstate.edu )

tyler.radniecki@oregonstate.edu https://orcid.org/0000-0002-5295-3562

\section{Biological Sciences - Article}

Keywords: COVID-19, community prevalence, wastewater

Posted Date: July 8th, 2021

DOI: https://doi.org/10.21203/rs.3.rs-690031/v1

License: (c) (1) This work is licensed under a Creative Commons Attribution 4.0 International License.

Read Full License 


\section{Wastewater-based epidemiology predicts COVID-19 community prevalence}

Blythe A. Layton ${ }^{1,2}$, Devrim Kaya ${ }^{1}$, Christine Kelly ${ }^{1}$, Kenneth J. Williamson ${ }^{2}$, Silke M.

Bachhuber $^{3}$, Peter G. Banwarth ${ }^{4}$, Jeffrey W. Bethel ${ }^{5}$, Katherine Carter ${ }^{6}$, Benjamin D. Dalziel ${ }^{3,7}$, Mark Dasenko ${ }^{6}$, Matthew Geniza ${ }^{6}$, Dana Gibbon ${ }^{6}$, Anne-Marie Girard ${ }^{6}$, Roy Haggerty ${ }^{8}$, Kathryn A. Higley ${ }^{9}$, Denise Hynes ${ }^{3,10}$, Jane Lubchenco ${ }^{3}$, Katherine R. McLaughlin ${ }^{11}$, F. Javier Nieto ${ }^{12}$, Aslan Noakes ${ }^{8}$, Matthew Peterson ${ }^{6}$, Adriana D. Piemonti ${ }^{2}$, Justin L. Sanders ${ }^{13}$, Brett M. Tyler ${ }^{6,14}$, and Tyler S. Radniecki ${ }^{1 *}$

${ }^{1}$ School of Chemical, Biological, and Environmental Engineering, Oregon State University, Corvallis, OR, USA

${ }^{2}$ Department of Research and Innovation, Clean Water Services, Hillsboro, OR, USA

${ }^{3}$ School of Biological and Population Health Sciences, Oregon State University, Corvallis, OR, USA

${ }^{3}$ Department of Integrative Biology, Oregon State University, Corvallis, OR, USA

${ }^{4}$ Benton County Health Department, Corvallis, OR, USA

${ }^{5}$ School of Biological and Population Health Sciences, Oregon State University, Corvallis, OR, USA

${ }^{6}$ Center for Genome Research and Biocomputing, Oregon State University, Corvallis, OR, USA

${ }^{7}$ Department of Mathematics, Oregon State University, Corvallis, OR, USA

${ }^{8}$ College of Science, Oregon State University, Corvallis, OR, USA

${ }^{9}$ School of Nuclear Science and Engineering, Oregon State University, Corvallis, OR, USA

${ }^{10}$ School of Social and Behavioral Health Sciences, Oregon State University, Corvallis, OR, USA

${ }^{11}$ Department of Statistics, Oregon State University, Corvallis, OR, USA 
${ }^{12}$ College of Public Health and Human Sciences, Oregon State University, Corvallis, OR, USA

${ }^{13}$ Carlson College of Veterinary Medicine, Oregon State University, Corvallis, OR, USA

${ }^{14}$ Department of Botany and Plant Pathology, Oregon State University, Corvallis, OR, USA

*Correspondence to: tyler.radniecki@oregonstate.edu

\section{$\underline{\text { Abstract }}$}

Wastewater-based epidemiology uses pooled wastewater samples to monitor community health and has been used extensively during the COVID-19 pandemic to track SARS-CoV-2 RNA shed by infected individuals into wastewater. Wastewater concentrations of SARS-CoV-2 RNA have been positively correlated with contemporaneous counts of COVID-19 cases, making it useful for following relative disease burden trends within a community. However, the statistical associations are too weak for wastewater-based epidemiology to reliably predict reported case counts, limiting its potential. Here we show that wastewater SARS-CoV-2 concentrations are highly correlated with the community prevalence estimated from 8 randomized household community surveys in 6 Oregon communities over a 10-month period. We found that wastewater-based epidemiology is a significantly better predictor of COVID-19 community prevalence than reported case counts, which suffer from systematic biases including variations in access to testing and underreporting of asymptomatic cases, even after accounting for uncertainty inherent in the wastewater and prevalence estimates by using Monte Carlo simulations. Additionally, our results show that wastewater-based epidemiology can identify the rise and fall of neighborhood-scale COVID-19 hot spots and provide rapid information about the presence of SARS-CoV-2 variants at the neighborhood- and city-scale through sequence analyses of the wastewater. These results validate the potential of wastewater-based epidemiology to be a 
quantitative method to predict the prevalence of SARS-CoV-2 and identify the presence of variants of concern in a given community or neighborhood, independent of availability and access to individual-level testing. These advantages in combination with its scalability, relatively modest cost and low labor requirements, makes integrating permanent wastewaterbased epidemiology infrastructure into public health systems a key component in creating pandemic-resilient cities in the future.

\section{$\underline{\text { Main }}$}

Wastewater-based epidemiology (WBE) has emerged as an effective and sensitive approach for monitoring COVID-19 presence in a community through the detection of the novel coronavirus (SARS-CoV-2) shed by infected individuals into wastewater ${ }^{1-5}$. While methods for COVID-19 WBE are still being refined, particularly with respect to optimizing sampling and virus concentration methods ${ }^{6-9}$, this approach has shown promise in monitoring COVID-19 infection trends and detecting community infections prior to reported cases ${ }^{5,10}$. WBE also has clear advantages in terms of cost (compared to traditional surveillance methods) and in areas where clinical testing is limited or residents are hesitant to participate ${ }^{1-5}$.

What has remained elusive is the quantitative relationship between viral concentrations in wastewater and community infection rates, as well as the representativeness of community viral genotype profiles from wastewater sequencing. These limitations are due to biological variability of SARS-CoV-2 infections, physical uncertainties of wastewater sampling, and inherent variability in case reporting. Biological variability comes from uncertainty and encompasses latent variation in the magnitude and duration of viral shedding in both symptomatic and asymptomatic individuals ${ }^{11-13}$. Physical uncertainties include representativeness of the 
wastewater samples, virus concentration and extraction methodologies, molecular detection methods and inhibition as well as genetic marker persistence and decay rates in sewage conveyance systems ${ }^{6,8,14-16}$. The inherent variability in case reporting results from underreporting of infections due to limited testing capacity, barriers in access to testing, testing avoidance, selfisolation of individuals with mild symptoms, and widespread asymptomatic transmission of the $\operatorname{virus}^{17}$.

In this paper, we examine SARS-CoV-2 burdens on communities through four lines of evidence: WBE data, clinically reported COVID-19 cases, sequence data obtained through nasal swabs as well as wastewater samples, and prevalence data estimated via nasal swabs of residents in randomly selected census blocks (trace.oregonstate.edu/community). From this examination, we demonstrate that $\mathrm{WBE}$ is a significantly better predictor of community prevalence than reported COVID-19 cases despite its inherent biological and physical variability. As such, we show that WBE can predict COVID-19 community prevalence (including both symptomatic and asymptomatic individuals), identify COVID-19 hot spots at the neighborhood scale, and estimate the community SARS-CoV-2 variant profile.

\section{Community Prevalence}

Over the course of 10 months, from May 2020 through March 2021, 8 COVID-19 prevalence surveys were conducted in 6 communities in Oregon, USA by Oregon State University's TRACE (Team-based Rapid Assessment of Community-level coronavirus Epidemics) project $^{18}$ (Extended Data Table 1). The selected communities represent a diverse cross-section of Oregon, ranging from a small coastal commercial fishing community (Newport, OR), to mid-sized and large university communities in the temperate Willamette Valley 
(Corvallis and Eugene, OR), mid-sized and large arid high desert communities (Redmond and Bend, OR), and a small agricultural community in eastern Oregon (Hermiston, OR).

An average of 517 individuals from 315 households (60\% average household participation rate) from 30 randomly selected census blocks were surveyed for the presence of SARS-CoV-2 in nasal swabs for each prevalence study. Nasal swabs were analyzed at the Oregon Veterinary Diagnostic Laboratory using the TaqPath COVID-19 Combo Kit (Applied Biosystems, Foster City, CA). The prevalence of SARS-CoV-2 within each community was calculated using design-weighted estimates accounting for the multi-stage sampling design and imperfect test sensitivity and specificity when at least one case was detected. A Bayesian approach combining observed data with active case counts within the community was used when zero cases were detected. The estimated SARS-CoV-2 prevalence, including both symptomatic and asymptomatic infections, ranged from 8 per 10,000 to 1,687 per 10,000 (Extended Data

\section{Table 2).}

During each prevalence study, composite samples (24-h time-weighted) were taken from the influent of each community's wastewater treatment plant. Samples were filtered through a mixed cellulose ester (HA-type) filter and stabilized with DNA/RNA Shield (Zymo Research, Irvine, CA). RNA was extracted from the filters and analyzed for SARS-CoV-2 RNA using U.S. CDC primers (N1 and N2) using reverse-transcriptase droplet digital PCR (RT-ddPCR). RTddPCR was chosen due to its superior sensitivity ${ }^{19,20}$, robustness against inhibitors $^{21}$, and its wide application in $\mathrm{WBE}^{15,22,23}$. The SARS-CoV-2 concentrations in the influent wastewater corresponding to the door-to-door nasal swab samples ranged from 2.92 to $5.13 \log _{10}$ gene copies per liter (gc/L) (Extended Data Table 2). 

week for 6 to 11 months following the same protocol as described above (Extended Data Figure 1). A comparison of the wastewater SARS-CoV-2 concentrations with the $\log _{10}$ of reported cases per 10,000 people (to normalize for differences in population) showed a general moderate positive correlation (Pearson's $r=0.71$ ). The accuracy of predicting reported COVID19 cases using WBE was also moderate (Root Mean Square Logarithmic Error $($ RMSLE) $=0.14$ and Mean Absolute Percentage Error $(\mathrm{MAPE})=0.29)$, with wastewater concentrations differing by up to 1.8 orders of magnitude representing the same number of reported COVID-19 cases per 10,000 people (Figure 1A). Similar correlation strengths and levels of accuracy were observed when each city was analyzed individually (Extended Data Figure 2).

Other studies have reported similar results, with WBE providing a relative sense of viral burden in a community and tracking its trend over time $e^{2,24,25}$. However, the moderate correlation between wastewater SARS-CoV-2 concentrations and reported COVID-19 cases limits the ability of WBE to predict community infections ${ }^{26,27}$. This moderate association has been attributed to a variety of factors related to the wastewater sample, including virus decay in sewage conveyance systems, variability in sampling and concentrating techniques, and variability in the magnitude and duration of shedding by infected individuals ${ }^{6,11,14}$. However, when the wastewater virus concentrations were compared with prevalence estimates that include both symptomatic and asymptomatic cases (Figure 1B), the positive correlation was much stronger (Pearson's $r=0.96$ ) and the accuracy was much higher, as demonstrated by the lower RMSLE (0.03) and MAPE (0.17) values. This correlation also suggests that the detection limit of our WBE method is 3 infections per 10,000 people. 
The strong correlation between estimated prevalence and wastewater concentrations suggests that the major source of variability in Figure 1A may not be due to the wastewater but rather the uncertainty associated with reported COVID-19 cases. To explore this possibility further, reported COVID-19 cases were correlated with estimated prevalence (Figure 1C). This correlation was moderately weaker (Pearson's $r=0.85)$ and the accuracy was lower (RMSLE $=$ 0.05 and MAPE $=0.31)$ than the wastewater versus prevalence correlation. In addition, we found wastewater concentrations to be a significantly better predictor of COVID-19 community prevalence than reported COVID-19 case counts, even after accounting for uncertainty inherent in the wastewater and prevalence estimates by using Monte Carlo simulations (Extended Data Figure 3). This demonstrates that it is the uncertainty of reported COVID-19 cases, rather than the wastewater data, that is the most significant source of variability.

Thus, when compared to a metric with much smaller uncertainties, such as the prevalence estimates presented in this study, wastewater data is quantitative and can accurately predict COVID-19 prevalence (Figure 1B). This may also explain why wastewater has shown significant predictive capabilities when compared to COVID-19 hospitalizations and deaths ${ }^{2,5,24}$. These metrics also have lower uncertainties than reported COVID-19 cases, which is likely to be impacted by unequal distribution of testing availability, asymptomatic individuals and individuals who do not seek testing for various reasons.

\section{$\underline{\text { Micro-sewershed Surveillance }}$}

In addition to predicting community-wide prevalence with high precision, we have also shown that WBE is a powerful method for detecting infection "hot spots" at the micro-sewershed (i.e., neighborhood) scale. In Newport, OR, USA, a community that experienced a significant 
COVID-19 outbreak during our study in mid-June 2020, wastewater SARS-CoV-2 concentrations in micro-sewersheds were significantly correlated with the positivity rate of random swab samples (Pearson's product-moment correlation $=0.64,95 \% \mathrm{CI}=0.32-0.83, \mathrm{df}=$ $22, p<0.001$ ) and reported cases (Pearson's product-moment correlation $=0.61,95 \% \mathrm{CI}=0.39$ $-0.76, \mathrm{df}=44, p<0.001)$. Similarly, the presence of SARS-CoV-2 in wastewater was significantly correlated with reported cases within each micro-sewershed (Fisher's exact test, CoV-2 was also significantly correlated between wastewater and random nasal swabs within each micro-sewershed (Fisher's exact test, OR could not be calculated, $95 \% \mathrm{CI}=2.16-\infty, p=$ $0.003, n=22)$.

The outbreak in Newport involved 185 reported cases linked to a local seafood processing plant in mid-June $2020^{28}$. During the peak of the outbreak, the TRACE team randomly selected and surveyed 569 individuals across the city using nasal swab assays and estimated a prevalence of 3.4\% (Extended Data Table 2). Simultaneously, wastewater samples were collected from the wastewater treatment plant influent and 22 pump stations located throughout the community of 10,853 people (Extended Data Figure 4). Each pump station drained a micro-sewershed with estimated populations ranging from 15 to 9,426 people (Extended Data Table 3). The random nasal swab and wastewater sampling were repeated three weeks later in July 2020. The outcome of this survey indicated a decrease in the community prevalence to an estimated 0.6\% (Extended Data Table 2).

The decrease in community prevalence corresponded with marked decreases in nasal swab positivity rates, reported COVID-19 cases, and wastewater SARS-CoV-2 concentrations in each micro-sewershed (Figure 2). It should be noted that due to the hierarchical flows between 
pump stations, the Northside micro-sewershed is receiving flow from the Bayfront microsewershed, which contains the Samaritan Pacific Communities Hospital (Extended Data Figure 4). Thus, the Northside micro-sewershed wastewater results may be capturing individuals who would not be linked to the Northside micro-sewershed by case reporting or random household surveillance (e.g., infected individuals at the Samaritan Pacific Communities Hospital).

Similar to our observations at the community scale, our WBE data correlated slightly more strongly with nasal swab positivity rates than with reported cases at the neighborhood scale. Thus, WBE may be generally more accurate at identifying hot spots of COVID-19 infections within a community than reported clinical cases. Other studies have used similar approaches to demonstrate the utility of wastewater monitoring at the building scale on college and university campuses ${ }^{29,30}$.

\section{Newport Community SARS-CoV-2 Genotype Profile}

Using Multi-Locus Sequence Typing ${ }^{31}$, two distinct viral variants, a B.1.399 lineage variant designated NA and a B.1 lineage variant designated NB, were detected both in the wastewater and among the individuals who tested positive during the June 2020 Newport survey (Extended

Data Table 4). The B.1.399/NA consensus most closely matched sequences found in Europe and then in California in March and April, 2020, respectively. The B.1/NB consensus sequence most closely matched that from Yakima County, Washington, on April 29, 2020, and sequences found in Europe in March 2020.

During the June survey (from a total of 569 samples), B.1.399/NA was detected in 77\% of the individuals tested positive (10/13) whereas B. 1 /NB was detected in $23 \%$ of the individuals 
tested positive (3/13) (Figure 3 and Extended Data Table 5). In the July survey, two individuals tested positive (from 550 samples). Although both samples both yielded low coverage sequence data, they were identified as B.1.1.291 by the international database, GISAID (https://www.gisaid.org/) and thus, were different than the individuals from the June survey.

In the wastewater samples, the fraction of viral RNA accounted for by each variant was estimated from the total fraction of variant reads summed across all single nucleotide polymorphism (SNP) positions specific to that variant. During the June survey, the viral variant distribution in the wastewater treatment plant influent was dominated by B.1.399/NA, accounting for $70 \%$ of the reads, while B. $1 / \mathrm{NB}$ accounted for a minority of the reads at $4 \%$ (Figure 3). This mirrors the observations made through the random nasal swab assays (77\% B.1.399/NA and 23\% B.1/NB), suggesting that wastewater sequences can both detect the type of viral variants present in a community and provide information on the relative distribution of the SARS-CoV-2 variants within that community.

B.1.399/NA was also dominant in 11 of the 12 positive micro-sewershed wastewater samples collected. During the June survey, B.1.399/NA accounted for 30-98\% of the total viral sequence reads across the micro-sewersheds, while during the July survey it accounted for 4892\% of the viral sequence reads across the micro-sewersheds (Extended Data Table 5). Additionally, while the abundance of B.1/NB was always in the minority, ranging from $0-52 \%$ of total virus sequence reads during the June survey and $0-11 \%$ of total virus sequence reads during the July survey, it was always detected in the wastewater of micro-sewersheds where B.1/NB was detected among individuals via random nasal swabs (Figure 3).

The only exception to this relationship was the Bayfront micro-sewershed (Extended Data Figure 4). In Bayfront, B.1/NB was not detected in the wastewater, while the single 
positive individual discovered in Bayfront carried B.1/NB. However, the Bayfront microsewershed houses the Samaritan Pacific Communities Hospital, which likely was releasing wastewater with a high concentration of B.1.399/NA from patients.

Finally, from the weeks of June 8 to November 30, 2020, five SARS-CoV-2 variants were detected consistently in wastewater samples from the Newport wastewater treatment plant (Figure 4A), representing at least 5\% of the sequence reads in samples from at least three weeks. Variant B.1.399/NA was the dominant variant during the weeks of June 8 to July 6, with lesser

amounts of B.1/NB detected. During the weeks of July 20 to 27, a B.1.369 sub-variant, designated EE (Extended Data Table 4B), was most abundant, and was also detected during the weeks of June 29 and August 3. From August 3 onwards, a B.1.2 sub-variant, designated FF (Extended Data Table 4B), was the most abundant variant detected. The detection of these variants in Newport broadly mirrored trends across the state of Oregon observed in individuals whose positive samples were sequenced and deposited in GISAID (Figure 4B). Interestingly, spikes observed in the wastewater treatment plant influent SARS-CoV-2 concentrations often corresponded to the appearance of a new dominant variant in the wastewater sequences (Figure 4A). This suggests that rises in viral RNA concentrations in WBE samples may signal the appearance of a new dominant variant. To our knowledge this is the first study of variant abundance in wastewater at the neighborhood scale, though others have sequenced SARS-CoV-2 in wastewater at the community scale ${ }^{32-34}$.

\section{$\underline{\text { Conclusion }}$}

We have demonstrated that WBE is a robust method that provides accurate quantitative predictions of COVID-19 prevalence in communities that are diverse in terms of size, location, 
access to testing, and pandemic stage. This finding greatly expands the potential of WBE beyond its current qualitative uses to track SARS-CoV-2 concentration trends in wastewater. We also have shown that WBE is a more reliable indicator of COVID-19 prevalence than

reported cases due the inherent variability and biases that are associated with reported cases. Additionally, we demonstrated that WBE can detect neighborhood-level COVID-19 hot spots, characterize the viral genetic diversity, and assess the importation of new cases through viral variant identification over time. Thus, we have shown that WBE is a powerful approach to accurately estimate COVID-19 prevalence and survey its genetic diversity. As such, WBE is clearly an essential tool in the efforts to bring the current pandemic to an end, and the establishment of national wastewater surveillance networks worldwide offers hope for improved surveillance of future epidemics caused by other pathogens.

\section{Main Text References}

1. Bivins, A. et al. Wastewater-Based Epidemiology: Global collaborative to maximize contributions in the fight against COVID-19. Environmental Science and Technology vol. 54 7754-7757 (2020).

2. Medema, G., Heijnen, L., Elsinga, G., Italiaander, R. \& Brouwer, A. Presence of SARSCoronavirus-2 RNA in sewage and correlation with reported COVID-19 prevalence in the early stage of the epidemic in the Netherlands. Environ. Sci. Technol. Lett. 7, 511-516 (2020).

3. Ahmed, W. et al. First confirmed detection of SARS-CoV-2 in untreated wastewater in Australia: A proof of concept for the wastewater surveillance of COVID-19 in the community. Sci. Total Environ. 728, 138764 (2020).

4. La Rosa, G. et al. First detection of SARS-CoV-2 in untreated wastewaters in Italy. Sci. Total Environ. 736, 139652 (2020).

5. Wurtzer, S. et al. Evaluation of lockdown effect on SARS-CoV-2 dynamics through viral genome quantification in waste water, Greater Paris, France, 5 March to 23 April 2020. Eurosurveillance 25, (2020).

6. Curtis, K., Keeling, D., Yetka, K., Larson, A. \& Gonzalez, R. Wastewater SARS-CoV-2 concentration and loading variability from grab and 24-1 hour composite samples. 
medRxiv 2020.07.10.20150607 (2020) doi:10.1101/2020.07.10.20150607.

7. Ahmed, W. et al. Comparison of virus concentration methods for the RT-qPCR-based recovery of murine hepatitis virus, a surrogate for SARS-CoV-2 from untreated wastewater. Sci. Total Environ. 139960 (2020) doi:10.1016/j.scitotenv.2020.139960.

8. LaTurner, Z. W. et al. Evaluating recovery, cost, and throughput of different concentration methods for SARS-CoV-2 wastewater-based epidemiology. Water Res. 197, 117043 (2021).

9. Whitney, O. N. et al. Sewage, Salt, Silica and SARS-CoV-2 (4S): An economical kit-free method for direct capture of SARS-CoV-2 RNA from wastewater. medRxiv 2020.12.01.20242131 (2020) doi:10.1101/2020.12.01.20242131.

10. Randazzo, W. et al. SARS-CoV-2 RNA in wastewater anticipated COVID-19 occurrence in a low prevalence area. Water Res. 181, 115942 (2020).

11. Jones, D. L. et al. Shedding of SARS-CoV-2 in feces and urine and its potential role in person-to-person transmission and the environment-based spread of COVID-19. Sci. Total Environ. 749, 141364 (2020).

12. Cheung, K. S. et al. Gastrointestinal manifestations of SARS-CoV-2 infection and virus load in fecal samples from a Hong Kong cohort: Systematic review and meta-analysis. Gastroenterology 159, 81-95 (2020).

13. Chen, Y. et al. The presence of SARS-CoV-2 RNA in the feces of COVID-19 patients. $J$. Med. Virol. 92, 833-840 (2020).

14. Bivins, A. et al. Persistence of SARS-CoV-2 in water and wastewater. Environ. Sci. Technol. Lett. 7, 937-942 (2020).

15. Bivins, A. et al. Within-day variability of SARS-CoV-2 RNA in municipal wastewater influent during periods of varying COVID-19 prevalence and positivity. medRxiv 2021.03.16.21253652 (2021) doi:10.1101/2021.03.16.21253652.

16. Pecson, B. M. et al. Reproducibility and sensitivity of 36 methods to quantify the SARSCoV-2 genetic signal in raw wastewater: Findings from an interlaboratory methods evaluation in the U.S. Environ. Sci. Water Res. Technol. 7, 504-520 (2021).

17. Gandhi, M., Yokoe, D. S. \& Havlir, D. V. Asymptomatic transmission, the Achilles' heel of current strategies to control Covid-19. N. Engl. J. Med. 382, 2158-2160 (2020).

18. Oregon State University TRACE COVID-19. trace.oregonstate.edu (2021).

19. Suo, T. et al. ddPCR: a more accurate tool for SARS-CoV-2 detection in low viral load specimens. Emerg. Microbes Infect. 9, 1259-1268 (2020).

20. Dong, L. et al. Highly accurate and sensitive diagnostic detection of SARS-CoV-2 by digital PCR. Talanta 224, 121726 (2021).

21. Cao, Y., Raith, M. R. \& Griffith, J. F. Droplet digital PCR for simultaneous quantification of general and human-associated fecal indicators for water quality assessment. Water Res. 70, 337-349 (2015).

22. Gonzalez, R. et al. COVID-19 surveillance in Southeastern Virginia using wastewaterbased epidemiology. Water Res. 186, 116296 (2020). 
23. D'Aoust, P. M. et al. Quantitative analysis of SARS-CoV-2 RNA from wastewater solids in communities with low COVID-19 incidence and prevalence. Water Res. 188, (2021).

24. Peccia, J. et al. Measurement of SARS-CoV-2 RNA in wastewater tracks community infection dynamics. Nat. Biotechnol. 38, 1164-1167 (2020).

25. Graham, K. E. et al. SARS-CoV-2 RNA in wastewater settled solids is associated with COVID-19 cases in a large urban sewershed. Environ. Sci. Technol. 55, 488-498 (2021).

26. Cao, Y. \& Francis, R. On forecasting the community-level COVID-19 cases from the concentration of SARS-CoV-2 in wastewater. Sci. Total Environ. 786, (2021).

27. Greenwald, H. D. et al. Interpretation of temporal and spatial trends of SARS-CoV-2 RNA in San Francisco Bay Area wastewater. medRxiv 2021.05.04.21256418 (2021) doi:10.1101/2021.05.04.21256418.

28. Oregon Health Authority COVID-19 weekly Report: Oregon's Weekly Surveillance Summary of the Nonvel Coronavirus (COVID-19). COVID-19 weekly Report: Oregon's Weekly Surveillance Summary of the Nonvel Coronavirus (COVID-19) https://www.oregon.gov/oha/PH/DISEASESCONDITIONS/DISEASESAZ/Emerging Respitory Infections/COVID-19-Weekly-Report-2020-08-05-FINAL.pdf (2020).

29. Spurbeck, R. R., Minard-Smith, A. \& Catlin, L. Feasibility of neighborhood and building scale wastewater-based genomic epidemiology for pathogen surveillance. Sci. Total Environ. 789, 147829 (2021).

30. Harris-Lovett, S. et al. Wastewater surveillance for SARS-CoV-2 on college campuses: Initial efforts, lessons learned and research needs. Int. J. Environ. Res. Public Health 18, 4455 (2021).

31. Ibarz Pavón, A. B. \& Maiden, M. C. J. Multilocus sequence typing. Methods Mol. Biol. 551, 129-140 (2009).

32. Crits-Christoph, A. et al. Genome sequencing of sewage detects regionally prevalent SARS-CoV-2 variants. MBio 12, 1-9 (2021).

33. Izquierdo-Lara, R. et al. Monitoring SARS-CoV-2 circulation and diversity through community wastewater sequencing, the Netherlands and Belgium. Emerg. Infect. Dis. 27, 1405-1415 (2021).

34. Agrawal, S., Orschler, L. \& Lackner, S. Metatranscriptomic analysis reveals SARS-CoV2 mutations in wastewater of the Frankfurt Metropolitan Area in Southern Germany. Microbiol. Resour. Announc. 10, (2021).

\section{Tables and Figures}



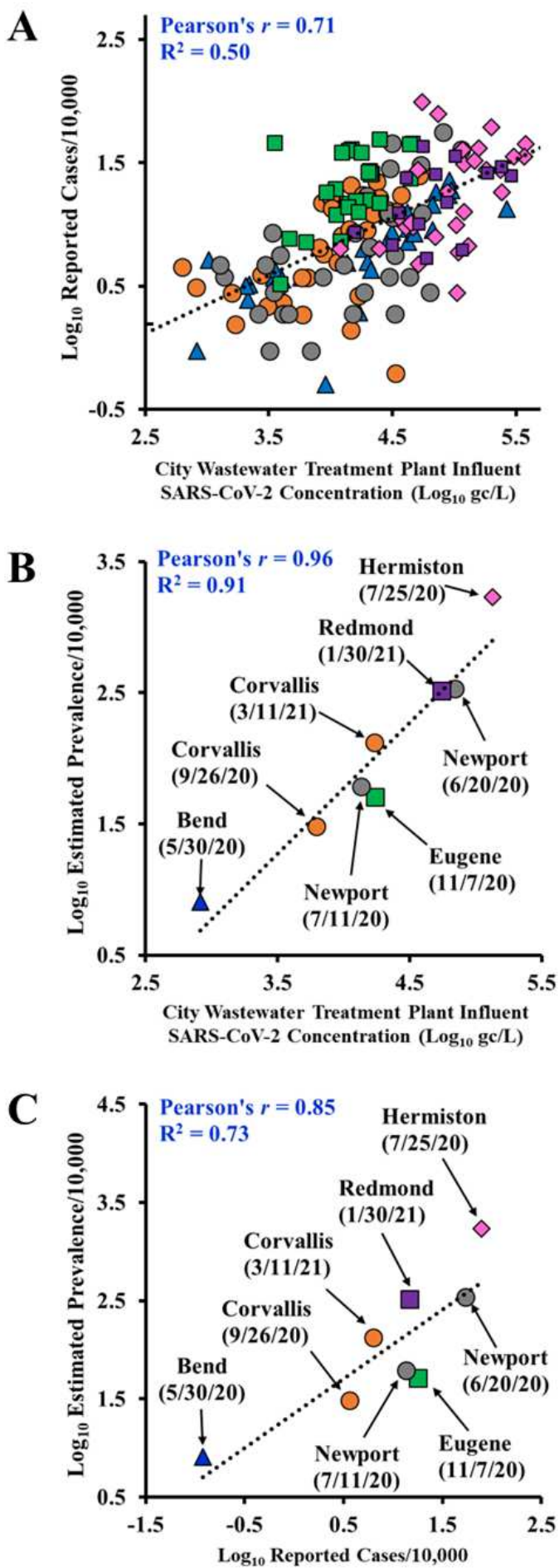

Figure 1. Wastewater Concentrations vs Reported COVID 19 Cases or Estimated Prevalence. (A) $\log _{10}$ of wastewater SARS-CoV-2 concentrations versus the $\log _{10}$ of weekly reported COVID-19 cases (reported by ZIP code) (B) Log 10 of wastewater SARS-CoV-2 concentrations versus the $\log _{10}$ of estimated prevalence and $(\mathbf{C}) \log 10$ of weekly reported COVID-19 cases (reported by ZIP code) versus the $\log _{10}$ of estimated prevalence for Bend ( $\boldsymbol{\Delta}$ ),

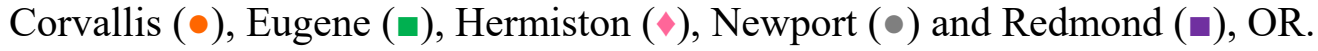



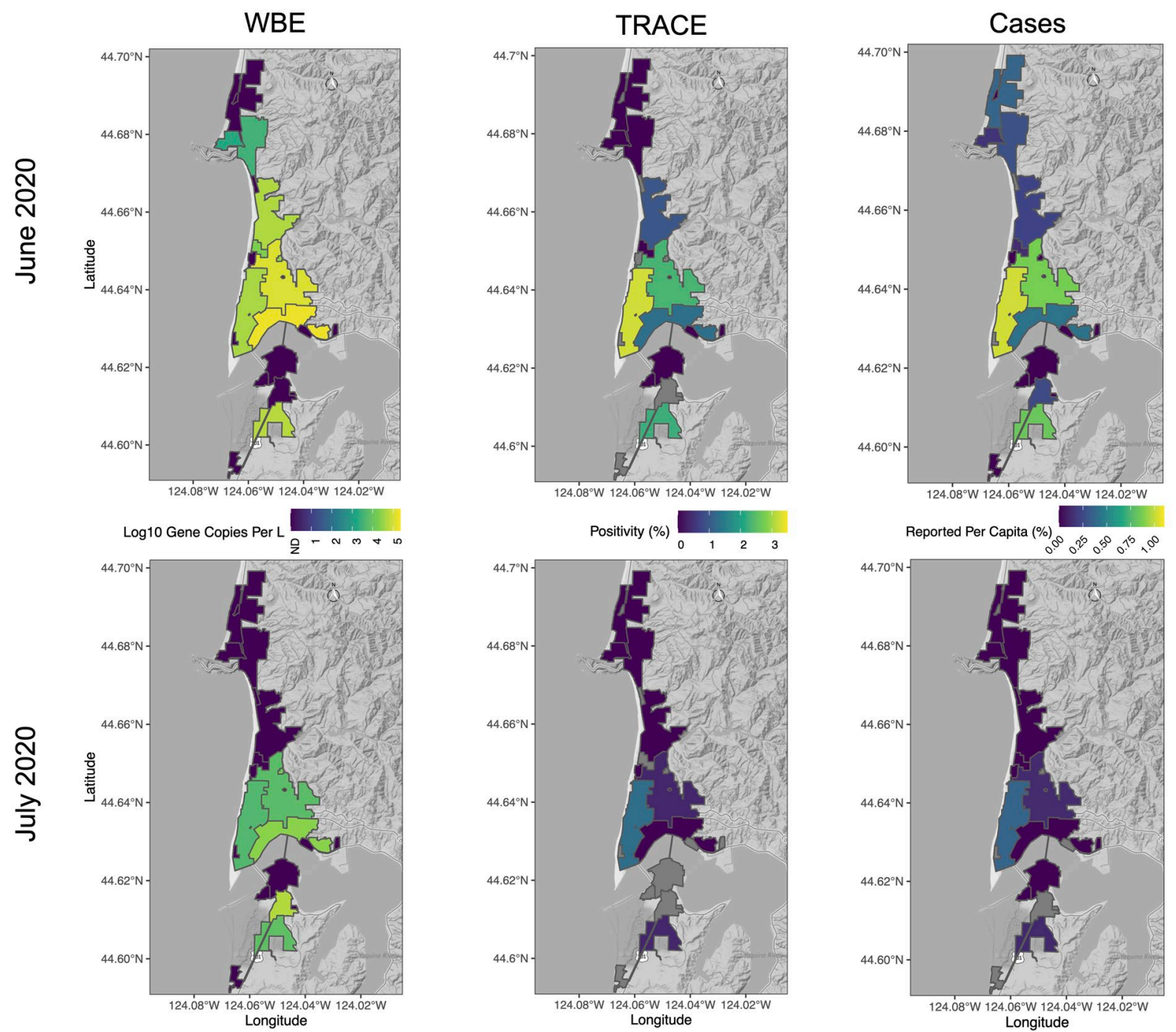

Figure 2. COVID-19 Burden Heat Maps. Wastewater SARS-CoV-2 concentrations (left column), \% positivity from community surveys (middle column) and \% reported cases per capita (right column) of the 22 micro-sewersheds sampled in Newport, OR. Wastewater and community surveys were conducted during June 18-19, 2020 (top row) and July 8-9, 2020 (bottom row); reported case windows were the 10 days prior to and including the sampling periods. 


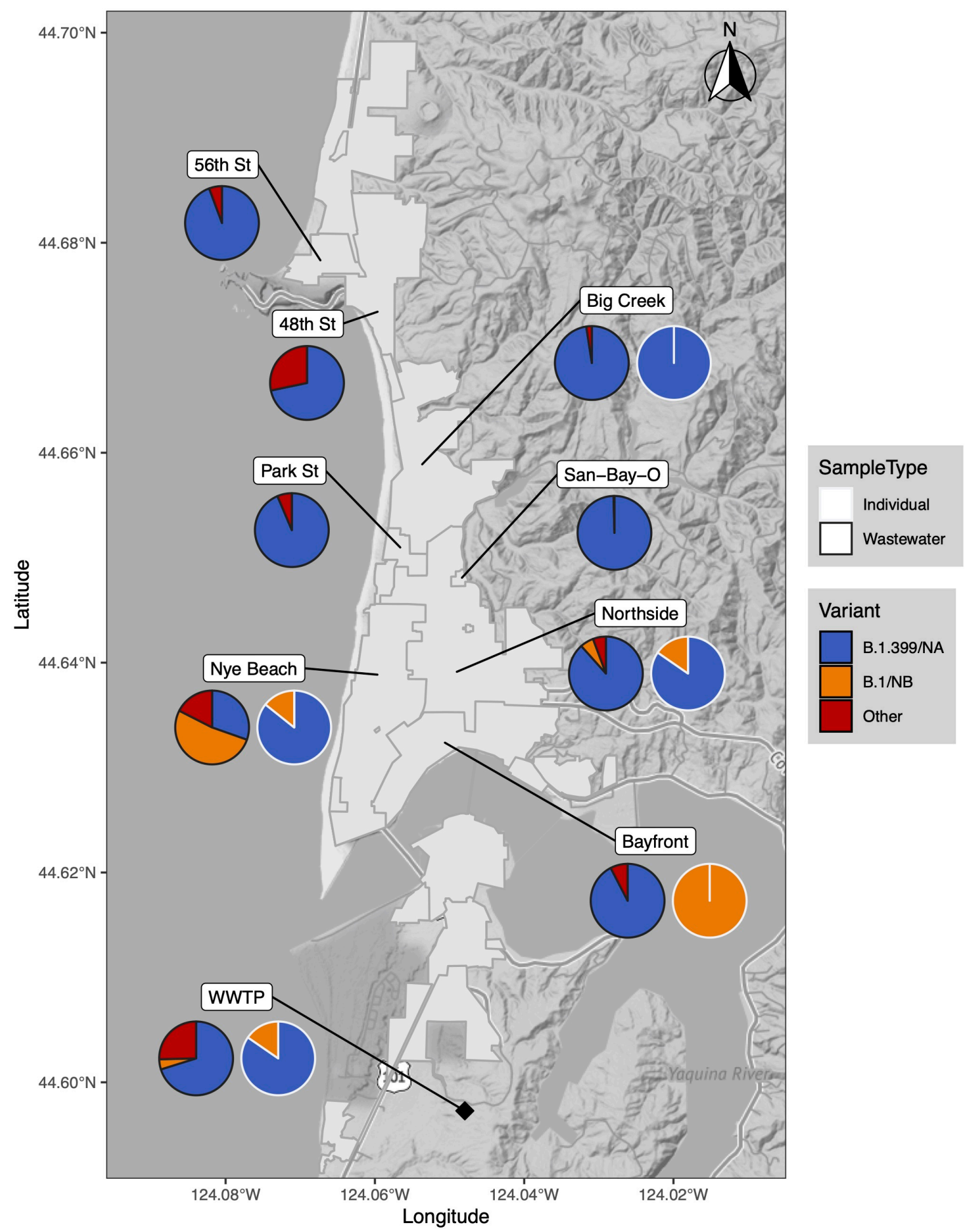

Figure 3. Spatial Distribution of SARS-CoV-2 Variants. The percent sequence reads of B.1.399/NA (A) and B.1/NB (B) located within the various Newport, OR micro-sewershed boundaries during the June 18-19, 2020 surveillance study. Sequences were obtained from both micro-sewershed wastewater as well as random household community surveys. 

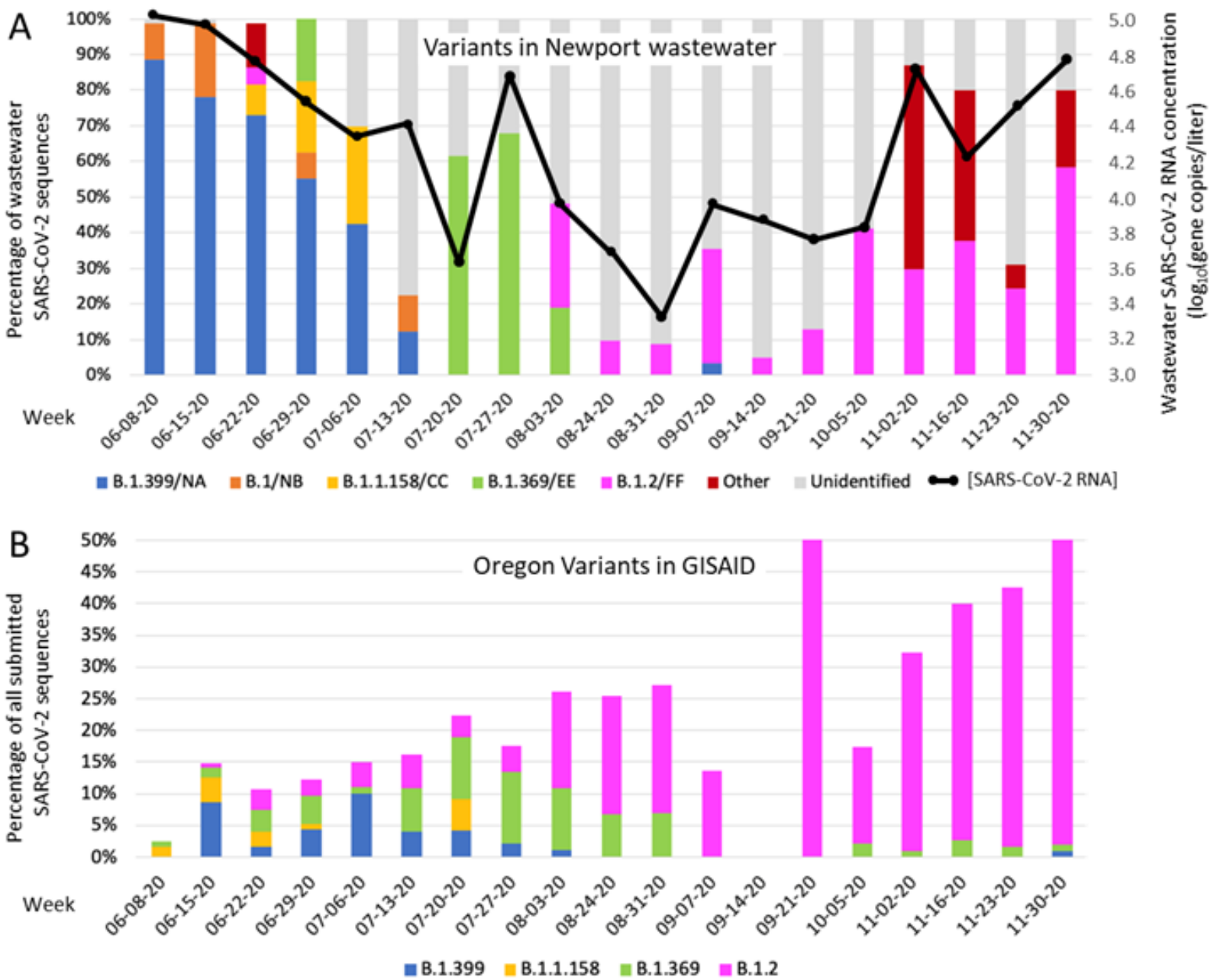

Figure 4. SARS-CoV-2 Variant Temporal Distribution. (A) The average estimated percent viral sequence reads of the indicated SARS-CoV-2 variant RNAs and the $\log _{10}$ SARS-CoV-2 concentrations quantified in the Vance Avery Wastewater Treatment Plant influent (Newport, OR) from June 10 to December 2, 2020. Each data point represents the mean of measurements collected during the week beginning on the date shown. Sequence data from some dates derived from a single measurement, and errors are expected to be comparable to those shown in Extended Data Table 5. (B) Percentage of all variants of the indicated lineages among SARSdate and deposited in GISAID. 


\section{Figure Legends}

Figure 1. Wastewater Concentrations vs Reported COVID 19 Cases or Estimated Prevalence. (A) $\log _{10}$ of wastewater SARS-CoV-2 concentrations versus the $\log _{10}$ of weekly reported COVID-19 cases (reported by ZIP code) (B) $\log _{10}$ of wastewater SARS-CoV-2 concentrations versus the $\log _{10}$ of estimated prevalence and (C) $\log _{10}$ of weekly reported COVID-19 cases (reported by ZIP code) versus the $\log _{10}$ of estimated prevalence for Bend $(\boldsymbol{\Delta})$,

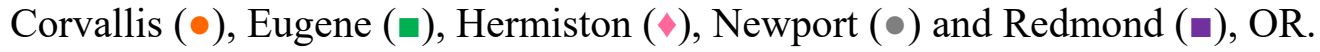

Figure 2. COVID-19 Burden Heat Maps. Wastewater SARS-CoV-2 concentration (left column), \% positivity from community surveys (middle column) and \% reported cases per capita (right column) of the 22 micro-sewersheds sampled in Newport, OR. Wastewater and community surveys were conducted during June 17-20, 2020 (top row) and July 8-9, 2020 (bottom row); reported case windows were the 10 days prior to and including the sampling periods.

Figure 3. Spatial Distribution of SARS-CoV-2 Variants. The percent sequence reads of B.1.399/NA and B.1/NB located within the various Newport, OR micro-sewershed boundaries during the June 17-20, 2020 surveillance study. Sequences were obtained from both microsewershed wastewater and random household community surveys.

Figure 4. SARS-CoV-2 Variant Temporal Distribution. (A) The average estimated percent viral sequence reads of the indicated SARS-CoV-2 variants and the $\log _{10}$ SARS-CoV-2 concentrations quantified in the Vance Avery Wastewater Treatment Plant influent (Newport, OR) from June 10 to December 2, 2020. Each data point represents the mean of measurements collected during the week beginning on the date shown. Error bars on the RNA concentrations represent the standard error of quadruplicate RT-ddPCR reactions from duplicate samples. Sequence data from some dates derived from a single measurement, and errors are expected to be comparable to those shown in Extended Data Table 5. Other indicates \% reads corresponding to known variants other than those shown. Unidentified indicates \% reads not attributable to any known variants (B) Percentage of all variants of the indicated lineages among SARS-CoV-2 sequences from samples collected in Oregon during the week beginning on the indicated date and deposited in GISAID. 


\section{Methods}

\section{Community swab sampling}

In total, TRACE collected 4,136 nasal swab samples from residents in 2,521 randomly selected households in Bend, Corvallis, Eugene, Hermiston, Newport and Redmond, Oregon from May 30, 2020 to March 14, 2021. The response rates ranged from 38-71\%, with an average response rate of $60 \%$ (Extended Data Table 2). The methods used for the random household sampling and prevalence estimate models are presented at the TRACE team website $(\text { trace.oregonstate.edu })^{18}$.

\section{Wastewater treatment plant sampling}

All wastewater treatment plant (WWTP) influent samples were comprised of 24-h timeweighted composites taken prior to primary treatment. The characteristics of each wastewater treatment plant is given in Extended Data Table 1. Twenty-two pump stations serving Newport, OR's Vance Avery WWTP sewershed were sampled hourly for $24 \mathrm{~h}$ from June 20-21 and July 11-12, 2020. Some pump stations were sampled twice within a single weekend, for a total of 52 pump station samples. The characteristics of each micro-sewershed (i.e., the area served by each pump station) and the distribution of samples are given in Extended Data Table 3.

For both WWTPs and pump stations, the 24-h composites consisted of hourly samples and were kept on ice during sampling. Samples collected on or before July 31, 2020 were frozen in $200 \mathrm{~mL}$ aliquots and stored for up to 33 days prior to concentration (median 6 days). After thawing in cold water baths, samples were concentrated using electronegative filtration, as previously described ${ }^{35}$. Briefly, all samples collected on or before July 10, 2020 were acidified to 
461 a final $\mathrm{pH}$ of 3.5 and magnesium chloride was added to a final concentration of $25 \mathrm{mM}$. Samples $462 \quad(30-40 \mathrm{~mL})$ were vacuum filtered through a $0.45 \mu \mathrm{m}$ pore size, $47 \mathrm{~mm}$ diameter mixed cellulose 463 ester electronegative filter (HAWP, Millipore, Bedford, MA, USA).

$464 \quad$ Influent samples collected after July 10, 2020 were filtered with no amendments as 465 preliminary data showed no statistical difference in viral recovery with unamended wastewater 466 (data not shown). Additionally, influent samples collected after July 31, 2020 were neither frozen 467 nor amended prior to filtration. In these samples, filtration occurred within $8 \mathrm{~h}$ of sample $468 \quad$ collection.

469 Once filtration was complete, the electronegative membranes were placed into $2 \mathrm{~mL}$ $470 \quad$ tubes containing a mix of $0.7 \mathrm{~mm}$ garnet and $0.5 \mathrm{~mm}$ glass beads, stabilized in $1 \mathrm{~mL}$ of 471 DNA/RNA Shield (Zymo Research, Irvine, CA, USA), and frozen until analysis. Field blanks of 472 deionized water were processed with every batch of samples.

473

\section{Molecular analysis: Nasal swabs}

Participant nasal swab samples were analyzed using the TaqPath COVID-19 Combo Kit (ThermoFisher), in accordance with the Instructions for Use as required by the Emergency Use Authorization under strict biosafety level 2 (BSL2) conditions. Nucleic acid isolation was performed using the MagMax Viral/Pathogen II Nucleic Acid Isolation Kit (Applied Biosystems/ThermoFisher, USA). Briefly, $200 \mu \mathrm{L}$ of transport medium from the swab sample was added to a single well of a KingFisher Deepwell 96-well plate containing $5 \mu \mathrm{L}$ Proteinase K. Each 96-well plate held 94 participant samples and one negative control well containing water. The last well was left empty to allow for the positive control to be added during the RT-PCR detection step. After sample addition, nucleic acid magnetic beads were resuspended, $10 \mu \mathrm{L}$ was 
added to $265 \mu \mathrm{L}$ binding solution and then added to the wells. MS2 phage control $(5 \mu \mathrm{L})$ was added to all wells as an extraction control and processed on a KingFisher Flex magnetic particle processor. Purified nucleic acids were eluted in $50 \mu \mathrm{L}$ MagMax elution solution. Eluted nucleic acid was stored at $-80^{\circ} \mathrm{C}$ unless RT-PCR was run within $2 \mathrm{~h}$ of extraction.

Detection of SARS-CoV-2 viral RNA was performed using the TaqPath RT-PCR COVID-19 Kit on a 7500 Fast Real-Time PCR Instrument (Applied Biosystems). Reactions were run in multiplex with primers and probes specific for three gene sequences specific to SARS-CoV-2: ORF1ab, N Protein, and S Protein. A primer and probe set was included to detect the MS2 phage added during the initial sample processing as an internal control to verify RNA extraction. The thermal protocol for the one-step real-time PCR was as follows: 2 min at $25^{\circ} \mathrm{C}$ UNG incubation, $10 \mathrm{~min}$ at $53{ }^{\circ} \mathrm{C}$ reverse transcription, $2 \mathrm{~min}$ at $95{ }^{\circ} \mathrm{C}$ activation, followed by 40 cycles of $3 \mathrm{sec}$ at $95^{\circ} \mathrm{C}$ denaturation and $30 \mathrm{sec}$ at $60{ }^{\circ} \mathrm{C}$ anneal/extension/detection. Results were analyzed using the SDS Software v1.5.1 and interpreted using the COVID-19 Interpretive Software (Applied Biosystems, v1.2).

\section{Molecular analysis: Wastewater}

Wastewater samples were homogenized with either $0.5 \mathrm{~mm}$ glass or $0.7 \mathrm{~mm}$ garnet beads in DNA/RNA Shield using either a Qiagen TissueLyser (Qiagen Inc, Germantown, MD) or BioSpec Mini-Beadbeater 16 (BioSpec Products, Inc, Bartlesville, OK) for 2 min. (Preliminary data indicated no difference in recovery between these homogenization methods; data not shown.) Beads and debris were pelleted by centrifugation at 12,000 ref for $1 \mathrm{~min}$. The lysate was transferred from each tube to a 96-well plate, and 200-400 $\mu \mathrm{L}$ was extracted using the MagMAX Viral/Pathogen kit on a KingFisher automated instrument (ThermoFisher Scientific, Waltham, 
MA) as described above. Purified RNA was eluted in $50 \mu \mathrm{L}$ MagMAX Elution Solution.

Extraction recovery from RNA extraction step was quantified with a commercial standard (Exact Diagnostics, Fort Worth, TX), and extraction blanks were included with every run. RNA was stored at $-80^{\circ} \mathrm{C}$ until analysis.

Two SARS-CoV-2 RNA targets (N1/N2) and an internal control (Human RNase P) were measured via RT-ddPCR using a commercial triplex assay (2019-nCoV CDC ddPCR Triplex Probe Assay, Bio-Rad catalog no. 12008202) using the One-Step RT-ddPCR Advanced Kit for Probes and run on a QX-200 ddPCR system (Bio-Rad, Hercules, CA). The primer and probe sequences were published previously ${ }^{36}$. Reactions were partitioned into droplets using an automated droplet generator (ADG). Twenty-two microliter reactions were prepared with $5.5 \mu \mathrm{L}$ template RNA, while the ADG only partitioned $20 \mu \mathrm{L}$, yielding an effective template volume of $5 \mu \mathrm{L}$. Each reaction had an average of 12,657 droplets (Std Dev $=1,783)$. Commercially prepared RNA standards and negative controls were included on each extraction plate and ddPCR plate (cat. no. COV019 and COV000, Exact Diagnostics, Fort Worth, TX). All samples and controls were analyzed in duplicate.

The one-step thermal cycling conditions were as follows: reverse transcription at $50{ }^{\circ} \mathrm{C}$ for $60 \mathrm{~min}$; enzyme activation at $95^{\circ} \mathrm{C}$ for $10 \mathrm{~min} ; 40$ cycles of denaturation at $94{ }^{\circ} \mathrm{C}$ for $30 \mathrm{~s}$ followed by annealing/extension at $55^{\circ} \mathrm{C}$ for $60 \mathrm{~s}$; enzyme inactivation at $98{ }^{\circ} \mathrm{C}$ for $10 \mathrm{~min}$; and lastly a $4^{\circ} \mathrm{C}$ hold for droplet stabilization, for a minimum of $30 \mathrm{~min}$ to a maximum of overnight. Finally, the amplification in the droplets was determined using the Bio-Rad droplet reader. All assay conditions were performed as specified in the Bio-Rad assay protocol ${ }^{37}$.

\section{RT-ddPCR data analysis}


Wells with less than 6000 droplets were omitted. Sample data with positive reactions were accepted only if the corresponding extraction blank and field blanks as well as the PCR negative and no-template controls were all negative for the N1/N2 targets. When averaging sample data across replicates, a value of $1 / 2$ the sample-specific limit of detection was substituted for nondetects. Reactions were regarded as positive if three or more droplets per well amplified in either target. Droplet clusters were manually called for each target using the QuantaSoft Analysis Pro software (Bio-Rad, Hercules, CA). All other analyses were conducted in R, version 4.1.0 ${ }^{38}$ with Rstudio Desktop, version 1.4.1717 $7^{39}$. Spatial graphics were created using the $\mathrm{sf}^{40}$, ggplot $2^{41}$, and ggmap $^{42}$ packages.

The N1 and N2 markers exhibited excellent agreement in the wastewater samples. The markers were concordant in $91.4 \%$ of reactions: $4.1 \%$ of reactions $(n=954)$ had a positive detection in $\mathrm{N} 1$ only (using a threshold of three positive droplets per reaction), and $4.5 \%$ of reactions were positive in N2 only. Quantitatively, the markers were also well aligned according to a simple linear model (slope $=0.94$ with N2 as the "response" variable, adjusted $\mathrm{r}^{2}=0.97, \mathrm{RMSE}=0.58$ copies per reaction). Accordingly, the $\mathrm{N} 1$ and $\mathrm{N} 2$ data were averaged together for all reported concentration values.

For limit of blank (LOB) determination, 104 reactions were run with the triplex assay across 3 plates using the Exact Diagnostics Negative Control as a template. Due to the nonnormal distribution of the results, the LOB was determined using a non-parametric (rank order) method with a false positive probability $(\alpha)$ of 0.05 . The LOB for N1 was 2.0 copies per reaction, and the LOB for N2 was 4.2 copies per reaction. Further details regarding the LOB results can be found in Extended Data and Supplementary Materials. 
1.

Equation 1: $L O D_{\text {predicted }}=L O B+2 * \operatorname{stDev}\left(\operatorname{CopiesPerReaction}{ }_{L O B}\right)$

Where stDev(CopiesPerReaction $\left.{ }_{L O B}\right)$ is the standard deviation of the copies per reaction from the LOB assay. The predicted LOD was subsequently tested by running 60 test reactions at

\section{cDNA library preparation and sequencing}

For cDNA synthesis, $11 \mu \mathrm{L}$ of lysate from positive wastewater or participant samples, were used for single-strand cDNA synthesis using the Thermo Superscript IV kit with the following modifications: no host gDNA/RNA removal steps are performed, no RNase H step is performed, and the reverse transcriptase incubation step at $50{ }^{\circ} \mathrm{C}$ is increased from $10 \mathrm{~min}$ to $30 \mathrm{~min}$.

The cDNA was used for amplification and sequencing using the Swift Amplicon® SARS-CoV-2 Panel (AL-COV48) together with Swift Amplicon® Combinatorial Dual Indexed Adapters (ALS1A96, AL-S1BA96, AL-S2A96, and AL-S2B96). The Swift Biosciences protocol was followed, except that, after optimization experiments, the volume of the G1 reagent was reduced to $25 \%$ of recommended level, resulting in an increase in read coverage for wastewater samples of 2- to 8-fold for the experiments described in this paper (with the release of version 2 of the Swift primer set, we no longer reduce this reagent). Individual libraries (30-96 samples) were quantified by fluorescence, normalized, and pooled for 2 x $150 \mathrm{bp}$ sequencing on a lane of an 
Illumina HiSeq3000 sequencer. Except for some initial sequencing experiments, libraries from individuals were prepared on different days and sequenced in different lanes than samples from wastewater, to reduce the possibility of contamination of sequences from low titer wastewater samples with sequences from high titer individual samples. Pooled libraries from wastewater samples were often run on 2 to 3 lanes of the Hi-Seq 3000 to increase read depth. Wastewater sequencing on the HiSeq3000 produced a median percentage of reads mapped of $0.86 \%$ compared to a median of $21.7 \%$ for nasal swab samples. In general, wastewater samples with an RNA concentration of $\log _{10}>4.0 \mathrm{gc} / \mathrm{L}$ reliably produced usable amounts of sequence. Samples with lower RNA concentrations produced variable amounts of sequence, and those below $\log _{10}$ $3.0 \mathrm{gc} / \mathrm{L}$ were routinely unsuccessful.

\section{Multi-Locus Sequence Typing}

After demultiplexing, Illumina primer sequences were trimmed using BBDuk, sequences were aligned to the reference sequence (Wuhan-Hu-1; NC_045512.2) using BWA mem, then SARSCov-2 primers were removed using Swift Biosciences Primerclip ${ }^{\mathrm{TM}}$ package. GATK then was used identify variants compared to the reference sequence and count the numbers of reference and variants reads at each SNP site; ploidy was set to 4 and down-sampling was not employed. When required, Integrated Genome Viewer (IGV) was used to manually inspect sequence alignments and variant calls.

In order to identify viral genotypes represented in wastewater RNA by multi-locus sequencing typing, sequences from individual samples from Oregon were used to define multilocus genotypes as a set of polymorphic sites that were unique to each variant and were not shared with any other variant known at the time (Extended Data Table 4). 
To estimate the fraction of each variant present in the wastewater RNA sequences, the number of reads supporting each variant were summed across all variant-specific SNP sites, then divided by the total number of reads spanning those SNP sites. At SNP sites where the total number of reads was greater than 100 , both the variant read number and total read number were scaled down to a total read number of 100 prior to the estimation calculation. At SNP sites with less than 100 total reads, the actual number of reads was used, thus decreasing the weight of those counts proportionally to the read coverage. After this estimation was conducted for each variant, the fractions were summed for all identified variants. If the sum was greater than 0.7 , it was assumed that the identified variants comprised all of the RNA molecules present and each fraction was divided by the total to normalize the total to 1.0. If the initial sum was less than 0.7 , it was assumed that the difference was comprised of RNA molecules from unidentified variants, and the fraction of RNA attributable to the unidentified variants was set to the difference between the total and 1.0. If the sum was greater than 1.5, the SNP data were manually reviewed to identify and remove artifacts such as SNPs miscalled by GATK (commonly $1 \mathrm{bp}$ indels) or SNPs that were unexpectedly shared between the variants present and hence double-counted. The custom software to conduct these calculations was implemented in $R$ and packaged into a SnakeMake pipeline ${ }^{43}$.

All individual sequences were deposited in GISAID (see Extended Data Table 6 for accession numbers) and all wastewater sequences were deposited in NCBI's short read archive, under BioProject PRJNA719837 (https://www.ncbi.nlm.nih.gov/bioproject/PRJNA719837)

\section{Reported Cases}


Weekly COVID-19 case data for the entire community was obtained for zip codes 97365 and 97366 from the Oregon Health Authority website ${ }^{28}$. For weeks when $<10$ cases occurred in a given zip code, they were reported as 1-9 cases, and a value of 5 cases was substituted in the calculations. Reported test results with location data were obtained with permission from the Lincoln County Health and Human Services Department, and public health officials anonymized the data by aggregating according to micro-sewershed prior to analysis.

\section{Monte Carlo Simulations}

To compare WBE and reported COVID-19 cases as predictors of community prevalence, Monte Carlo simulations were performed to account for the uncertainty in the point estimates for each sampling event. For each simulation, a new wastewater concentration $\left(\log _{10} \mathrm{gc} / \mathrm{L}\right)$ was re-drawn for each community sample from a Gaussian distribution with mean equal to the point estimate and standard deviation equal to the standard error of the point estimate. Similarly, a new prevalence was re-drawn for each community from a method-specific distribution: a truncated Gaussian distribution with mean equal to the point estimate, standard deviation equal to the standard error of the point estimate, and lower truncation bound equal to zero when the designbased estimator was used; or a Beta distribution with shape and scale parameters estimated using optimization to fit the posterior mean and $95 \%$ credible interval when the Bayesian estimator was used $^{44}$. The reported COVID-19 case numbers are not re-drawn. For each simulation, a simple linear regression model is fit using the new wastewater concentration draw to predict the $\log _{10}$ of the new community prevalence draw, and a separate model is fit using the $\log _{10}$ of the observed COVID-19 case count to predict the $\log _{10}$ of the new community prevalence draw. For each model, the slope, intercept, and $\mathrm{R}^{2}$ value are recorded. 
10,000 simulations were performed, and the results are shown in Extended Data Figure

644 3. The horizontal lines about the observed points indicate \pm 1 SE. The vertical lines indicate \pm 1

645 SE for the design-based estimates and the $68 \%$ credible interval for the Bayesian estimates. Each

646 of the middle $95 \%$ (based on slope) of the 10,000 different regression lines are shown in pale

647 gray with high transparency, so the darker band indicates more lines. This gives a sense of the

648 uncertainty of the relationships between the different variables.

649

650

651

652

653

654

655

656

657

658

659

660

661

662

663

664

665

The median $\mathrm{R}^{2}$ for the WBE model is 0.82 compared with 0.71 for the reported cases model. A Wilcoxon rank-sum test for whether the two distributions for $\mathrm{R}^{2}$ have a location shift of 0 versus the alternative that the $\mathrm{WBE} \mathrm{R}^{2}$ distribution has a positive shift gives a $p$-value of $<0.0001$. Thus, even after accounting for the uncertainty inherent in the WBE and community prevalence estimates, the difference between the WBE and reported cases median $\mathrm{R}^{2}$ values is significant, and wastewater concentration has a larger median $\mathrm{R}^{2}$. For each simulation, the two non-nested regression models can also be directly compared using Vuong's test, which is a likelihood-ratio-based test for model selection using the Kullback-Leibler information criterion $^{45,46}$. Vuong's test finds evidence that the WBE model fits significantly better than the reported cases model $(p<0.05) 53 \%$ of the time. The reported cases model only fits significantly better $2 \%$ of the time; the models cannot be distinguished on the remaining occasions. Although Vuong's test cannot determine if the preferred model is the true model, the high $\mathrm{R}^{2}$ value $(0.91$ using the observed data) and low RMSLE (0.03) and MAPE (0.17) are indicative of a good fit. Taken together, these two tests suggest that WBE is a significantly better predictor of community prevalence than reported COVID-19 case counts. 
Methods References

668

669

670

671

672

673

674

675

676

677

678

679

680

681

682

683

684

685

686

687

688

689

690

691

692

693

694

695

696

697

35. Steele, J. A., Blackwood, A. D., Griffith, J. F., Noble, R. T. \& Schiff, K. C. Quantification of pathogens and markers of fecal contamination during storm events along popular surfing beaches in San Diego, California. Water Res. 136, 137-149 (2018).

36. Lu, X. et al. US CDC real-time reverse transcription PCR panel for detection of severe acute respiratory syndrome Coronavirus 2. Emerg. Infect. Dis. 26, 1654-1665 (2020).

37. Bio-Rad SARS-CoV-2 ddPCR Kit: Instructions for Use. (2020).

38. R Code Team, R: A Language and Environment for Statistical Computing (R Foundation for Statitistical Computing). (2020).

39. RStudio Team, RStudio: Integrated Development Environment for R (RStudio, PBC). (2020).

40. Pebesma, E. Simple features for R: Standardized support for spatial vector data. The $R$ Journal 10, 439-446 (2018).

41. Wickham, H. ggplot2: Elegant graphics for data analysis. (Springer-Verlag, 2016).

42. Kahle, D. \& Wickham, H. ggmap: Spatial visualization with ggplot2. The R Jounral 5, 144-161 (2013).

43. Köster, J. et al. Sustainable data analysis with Snakemake. F1000Research 10, 33 (2021).

44. Devleesschauwer, B. et al. prevalence: Tools for prevalence assessment studies. R package version 0.4.0. http://cran.r-project.org/package=prevalence.

45. Vuong, Q. H. Likelihood Ratio Tests for model selection and non-nested hypotheses. Econometrica 57, 307 (1989).

46. Merkle, E. \& You, D. nonnest2: Tests of non-nested models. R package version 0.5-5. (2020).

47. Decaro, N. et al. Detection of bovine coronavirus using a TaqMan-based real-time RTPCR assay. J. Virol. Methods 151, 167-171 (2008).

\section{Acknowledgements}

The authors are grateful to the Public Works Departments of the cities of Bend, Corvallis, Eugene, Hermiston, Newport and Redmond, the Benton County Health Department, the Deschutes County Health Services, the Lane County Public Health Department, the Lincoln 
County Health and Human Services Department, the Umatilla County Public Health Department and the Oregon Health Authority for their support in sample collection and public health data acquisition. We also thank the staff of Clean Water Services, especially Leila Barker and interns Andrea George and Kestrel Bailey, the Oregon Veterinary Diagnostic Laboratory (Andree Hunkapiller, Noah Lawler, Donna Mulrooney, Brandy Nagamine, and Ali Al-Fotis) and Michael

\section{Author Contributions} Harry from OSU's School of Chemical, Biological and Environmental Engineering. Funding for this work was provided by an NSF RAPID grant (\#2027679), the David and Lucille Packard Foundation, Pacific Source Health Plans, and the Oregon State University Foundation.

B.A.L. generated and analyzed wastewater ddPCR data, wrote R scripts for automated ddPCR data cleaning and processing, drafted the original version of the manuscript, and created the spatial graphics.

D.K. generated wastewater ddPCR data, extracted COVID-19 cases from reports, developed surrogate $(\mathrm{BCoV})$ quantification assay and analyzed wastewater samples for recovery, contributed significantly to the writing and editing of the manuscript.

C.K. is the co-PI of the wastewater portion of the project. She helped create the experimental design for the sampling and testing of wastewater, including method development, and actively participated in the collection of wastewater samples. She contributed significantly to data interpretation, writing and editing of the manuscript. 
K.J.W. helped create the experimental design for the sampling and testing of wastewater, including method development, and actively participated in the collection of wastewater samples. He contributed to writing and editing of the manuscript.

S.M.B contributed to the implementation of the work and edited the manuscript.

P.G.B. extracted and analyzed the case report data, and contributed to the analysis and interpretation of the data and to writing and editing the manuscript.

J.W.B. is the lead PI of the community survey data collection portion of the project. He codeveloped the data collection protocol for the community survey and contributed to editing the manuscript.

K.C. developed and optimized the protocol used to extract RNA from wastewater, contributed to producing the sequence data shown in the paper and editing the manuscript.

B.D.D. contributed to the design and implementation of the work, to the analysis and interpretation of data and to writing and editing of the manuscript.

M.D. designed the sequence strategy used in the project and contributed to producing the sequence data shown in the paper and editing the manuscript.

M.G. co-developed the wastewater sequence analysis pipeline, jointly analyzed the sequence data shown in the paper, and contributed to editing the manuscript.

D.G. co-developed the wastewater sequence analysis pipeline, jointly analyzed the sequence data shown in the paper, and contributed to editing the manuscript. 
A-M.G. developed and optimized the ddPCR and sequencing protocols used in the project, and contributed to producing the sequence data shown in the paper and editing the manuscript.

R.H. contributed to the design and implementation of the work, to the analysis and interpretation 740 of data and to writing and editing the manuscript.

K.A.H. contributed to the design and implementation of the work, to the analysis and interpretation of data, and to the editing of the manuscript.

D.H. contributed to the design and implementation of the data acquisition protocols for the community surveys and contributed to editing the manuscript.

J.L. contributed to the design and implementation of the work, to the analysis and interpretation of data and to writing and editing the manuscript.

K.R.M. co-developed the sampling design for the community prevalence surveys, produced prevalence estimates, contributed to other statistical analyses, and contributed to editing the manuscript.

F.J.N. contributed to the design and implementation of the work, to the analysis and interpretation of data and to writing and editing the manuscript. A.N. contributed to the design and implementation of the work, to the analysis and interpretation of data and to writing and editing the manuscript.

M.P. designed and implemented the data acquisition and management pipelines for the community surveys and for the Illumina sequencing and contributed to editing the manuscript. 
757 A.D.P. created the Newport micro-sewershed shapefiles and generated the demographic data that 758 corresponded with each micro-sewershed and contributed to the writing and editing of the 759 manuscript.

760 J.L.S is the lead PI of the diagnostic laboratory component of the project. He contributed to the 761 design and implementation of the work, to the analysis and interpretation of data and writing and 762 editing of the manuscript.

763 B.M.T. designed the integrated sequencing and analysis of wastewater and individual samples, 764 and contributed to the data analysis, writing and editing of the manuscript.

\section{Competing Interest Declaration}

T.S.R. is the lead PI of the wastewater portion of the project. He helped create the experimental design for the sampling and testing of wastewater, including method development, and actively participated in the collection of wastewater samples. As corresponding author, he contributed significantly to data interpretation, writing and editing of the manuscript. 
775 Supplementary Information is available for this paper.

776 Correspondence and requests for materials should be addressed to Tyler S. Radniecki at

$777 \quad$ tyler.radniecki@,oregonstate.edu.

778 Reprints and permissions information is available at www.nature.com/reprints.

Data Availability

All individual sequences were deposited in GISAID (see Extended Data Table 6 for

\section{Code Availability} accession numbers) and all wastewater sequences were deposited in NCBI's short read archive, under BioProject PRJNA719837 (https://www.ncbi.nlm.nih.gov/bioproject/PRJNA719837). Data from community prevalence surveys is in Extended Data Table 2. Wastewater ddPCR data supporting the findings of this study are located within the paper and its supplementary information files. 

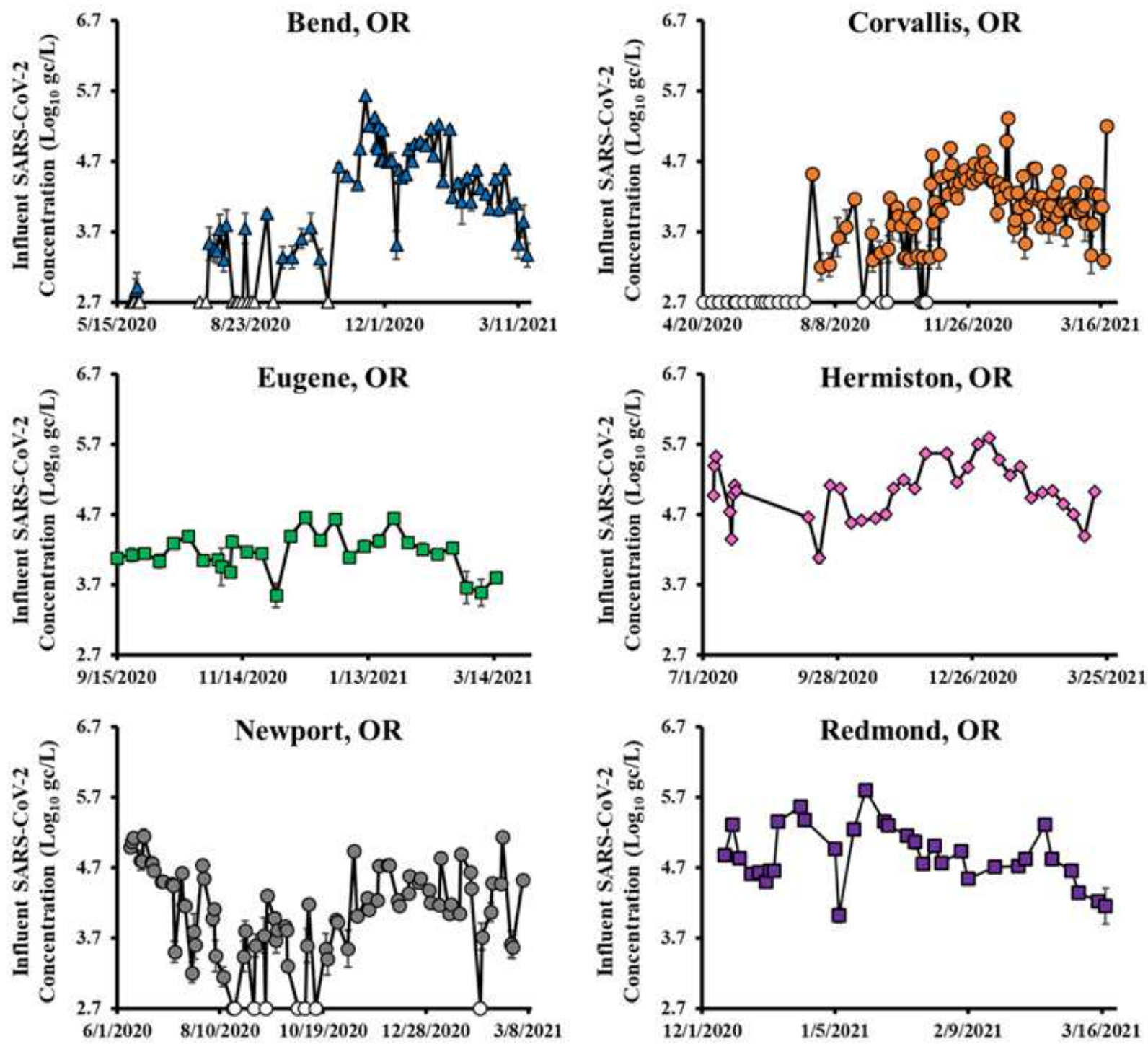

Extended Data Figure 1. Wastewater Time Series Data. The $\log _{10} \mathrm{SARS}-\mathrm{CoV}-2$ concentration $\left(\log _{10} \mathrm{gc} / \mathrm{L}\right)$ over time for each participating city. Open symbols represent values below detection limits. Error bars represent the standard error of quadruplicate RT-ddPCR measurements from duplicate samples. 

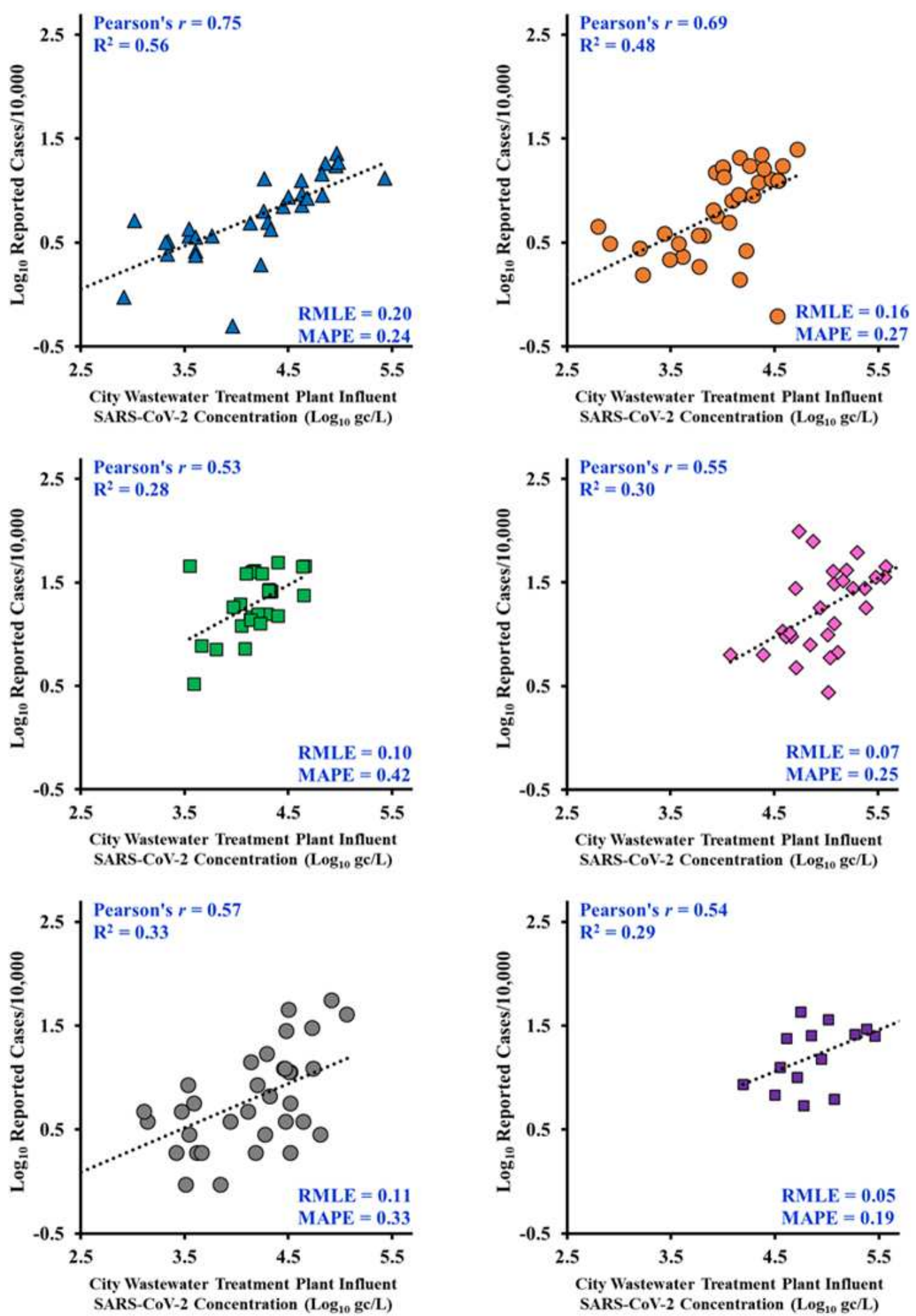

Extended Data Figure 2. Wastewater Concentrations vs Reported COVID 19 Cases for Individual Cities. $\log _{10}$ of wastewater SARS-CoV-2 concentrations versus the $\log _{10}$ of weekly reported COVID-19 cases normalized to each city's population and reported per 10,000 population (reported by ZIP code) for Bend ( $\Delta$ ), Corvallis (•), Eugene ( $\square$ ), Hermiston ( $\diamond)$, Newport (•) and Redmond ( $\bullet$ ), OR. 

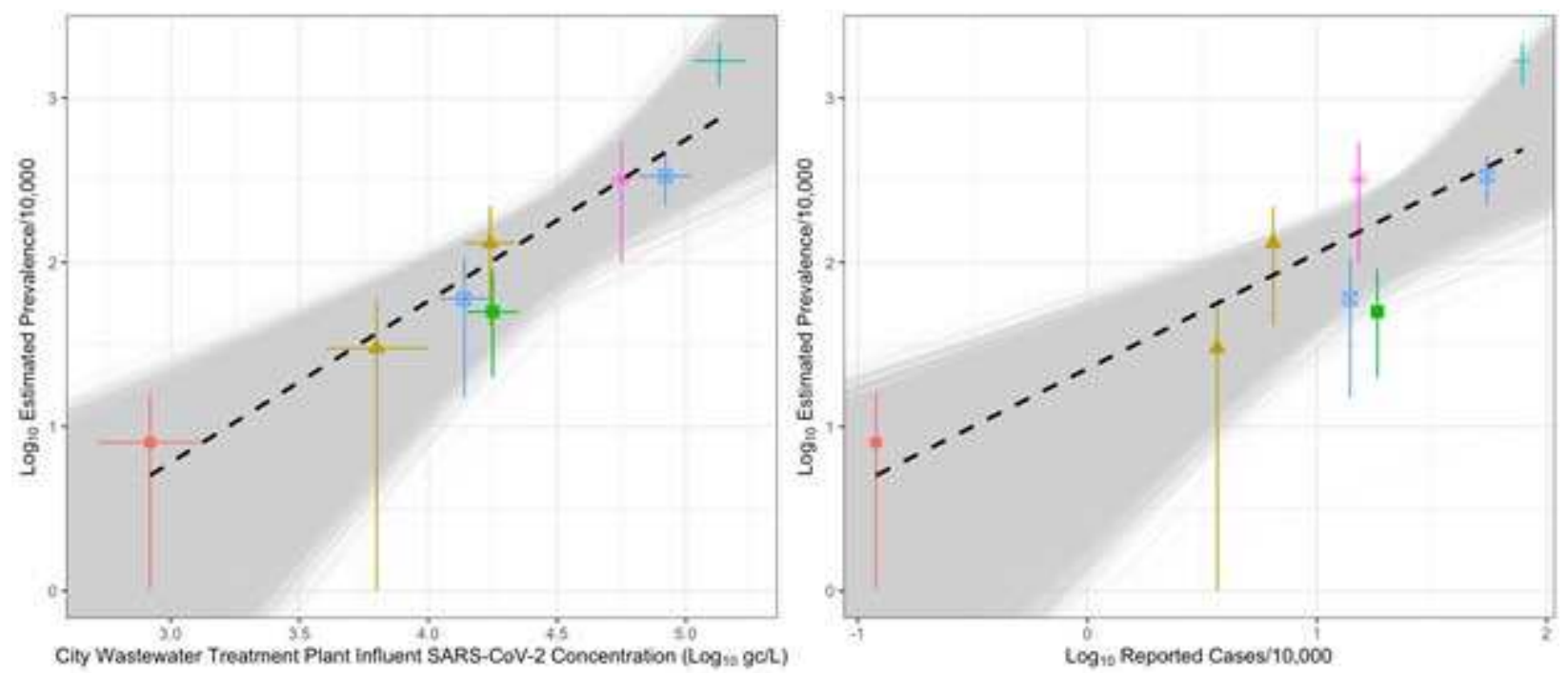

\section{Extended Data Figure 3. Estimated Prevalence vs. Wastewater Concentration and} Reported Cases with Uncertainty from Monte Carlo Simulations. (Left) $\log _{10}$ of wastewater SARS-CoV-2 concentrations versus the $\log _{10}$ of estimated prevalence, where the regression line from observed data is shown in a dashed black line. Horizontal and vertical segments indicate one standard error or a $68 \%$ credible interval. The gray band is made up of individual regression lines from Monte Carlo simulations. (Right) $\log _{10}$ of wastewater SARS$\mathrm{CoV}-2$ concentrations versus the $\log _{10}$ of reported cases, where the regression line from observed data is shown in a dashed black line. Vertical segments indicate one standard error or a $68 \%$ credible interval. The gray band is made up of individual regression lines from Monte Carlo simulations. of individual regression lines from Monte Carlo simulations. 

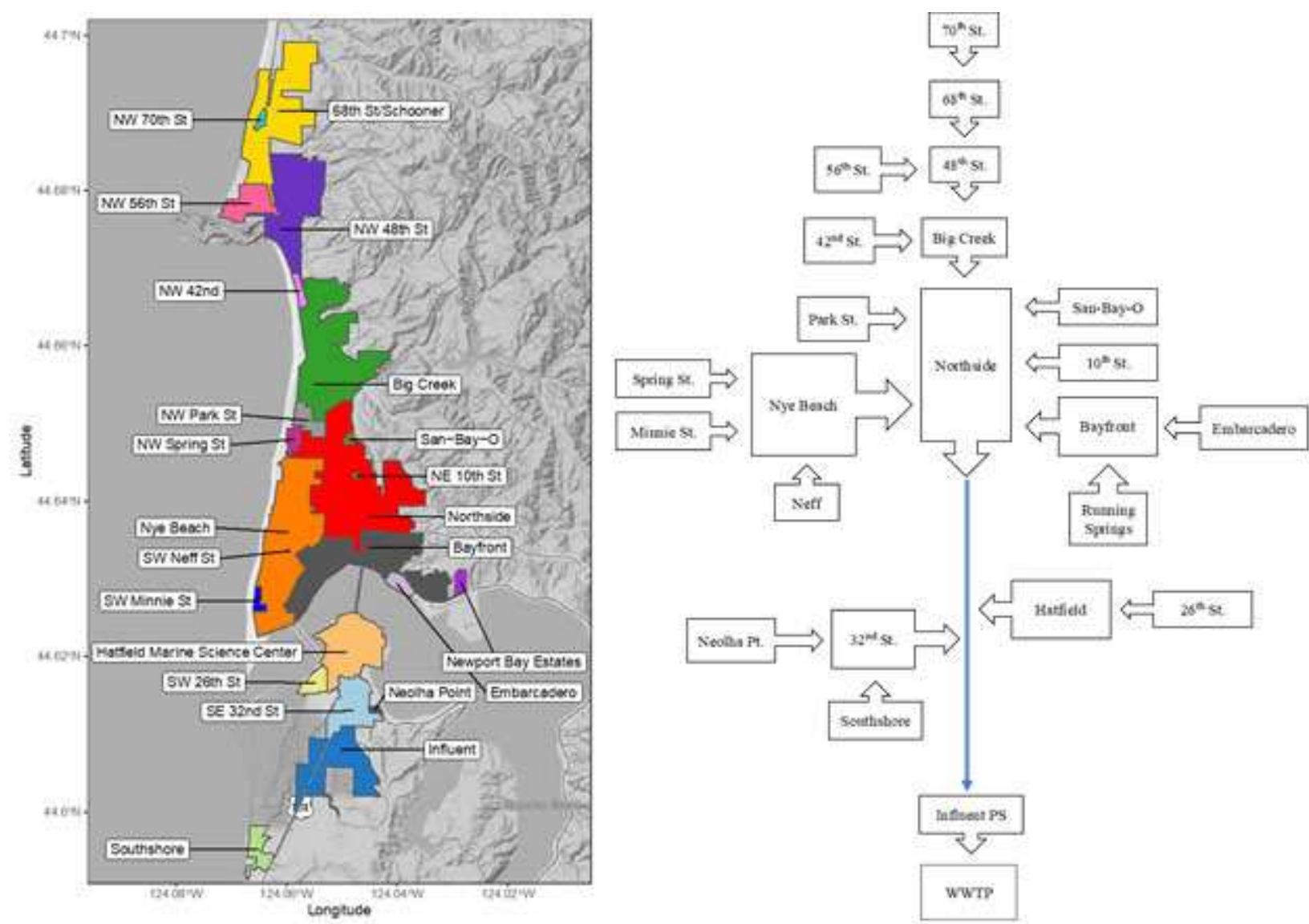

Extended Data Figure 4. Newport, OR Micro-sewersheds. (Left) Location and name of the 22 pump stations and their associated micro-sewersheds sampled in Newport, OR. (Right) Flow chart depicting the hierarchical relationships between pump stations. The blue arrow represents a forced main running under the Yaquina Bay and southward toward the wastewater treatment plant. 
Extended Data Table 1. City and Wastewater Treatment Plant Statistics

Extended Data Table 2. SARS-CoV-2 Prevalence Study Statistics. Samples with an (*) indicate zero positive cases were observed and so the prevalence estimate utilizes additional data on active infections in the community. s.e.: standard error

\begin{tabular}{|c|c|c|c|c|c|c|c|c|}
\hline City & Date & $\begin{array}{l}\text { Number of } \\
\text { Participating } \\
\text { Households }\end{array}$ & $\begin{array}{c}\text { Household } \\
\text { Participation } \\
\text { Rate }\end{array}$ & Samples & $\begin{array}{c}\text { Estimated } \\
\text { Prevalence } \\
\text { per } 10,000\end{array}$ & $\begin{array}{c}\text { Lower } \\
\text { Bounds } \\
\text { per } 10,000\end{array}$ & $\begin{array}{c}\text { Upper } \\
\text { Bounds } \\
\text { per } 10,000\end{array}$ & $\begin{array}{c}\text { Wastewater } \\
\text { SARS-CoV-2 } \\
\text { Concentration } \\
\left(\log _{10} \pm \text { s.e. }\right)\end{array}$ \\
\hline Bend, OR & May $30-31,2020$ & 342 & $68 \%$ & 615 & $8^{*}$ & 1 & 38 & $2.9 \pm 0.2$ \\
\hline Newport, OR & June $20-21,2020$ & 336 & $71 \%$ & 569 & 335 & 109 & 562 & $4.9 \pm 0.1$ \\
\hline Newport, OR & July $11-12,2020$ & 338 & $70 \%$ & 550 & 60 & 0 & 150 & $4.1 \pm 0.1$ \\
\hline Hermiston, OR & July $25-26,2020$ & 249 & $44 \%$ & 469 & 1687 & 714 & 2660 & $5.1 \pm 0.1$ \\
\hline Corvallis, OR & Sept. $26-27,2020$ & 354 & $71 \%$ & 580 & 30 & 0 & 89 & $3.8 \pm 0.2$ \\
\hline Eugene, OR & Nov. $7-8,2020$ & 304 & $49 \%$ & 463 & $50^{*}$ & 10 & 140 & $4.3 \pm 0.1$ \\
\hline Redmond, OR & Jan $29-31,2021$ & 251 & $38 \%$ & 376 & 320 & 0 & 760 & $4.8 \pm 0.0$ \\
\hline Corvallis, OR & Mar 12-14, 2021 & 347 & $67 \%$ & 514 & 131 & 0 & 310 & $4.2 \pm 0.1$ \\
\hline
\end{tabular}

871

872

873

\begin{tabular}{|c|c|c|c|c|c|c|}
\hline City & County & $\begin{array}{c}\text { Population } \\
\text { Served }\end{array}$ & $\begin{array}{c}\text { Average Daily } \\
\text { Wastewater Flow }\end{array}$ & $\begin{array}{c}\text { Sewer System } \\
\text { Type }\end{array}$ & Collection Type & Sample Matrix \\
\hline Bend, OR & Deschutes & 100,421 & 6.1 MGD & Separated & 24 h Composites & Wastewater Influent \\
\hline Corvallis, OR & Benton & 58,856 & 18.1 MGD & Combined* & 24 h Composites & Wastewater Influent \\
\hline Eugene, OR & Lane & 235,852 & 52.3 MGD & Separated & 24 h Composites & Wastewater Influent \\
\hline Hermiston, OR & Umatilla & 17,782 & 1.2 MGD & Separated & 24 h Composites & Wastewater Influent \\
\hline Newport, OR & Lincoln & 10,853 & 1.4 MGD & Separated & 24 h Composites & Wastewater Influent \\
\hline Redmond, OR & Deschutes & 32,421 & 2.3 MGD & Separated & $24 \mathrm{~h}$ Composites & Wastewater Influent \\
\hline
\end{tabular}

*3.5 $\mathrm{mi}^{2}$ are combined wastewater and stormwater out of a $8.6 \mathrm{mi}^{2}$ sewershed. 


\begin{tabular}{|c|c|c|c|c|c|c|}
\hline Pump Station & $\begin{array}{c}\text { Drainage } \\
\text { Area (acres) } \\
\end{array}$ & $\begin{array}{c}\text { Percent } \\
\text { Residential }\end{array}$ & $\begin{array}{l}\text { Estimated } \\
\text { Population }\end{array}$ & Collection Type & Sample Matrix & Sample Dates \\
\hline $10^{\text {th }} \mathrm{St}$. & 1.45 & 100 & 15 & 24 h Composites & Wastewater Conveyance & $6 / 18 / 2020 ; 7 / 8 / 2020$ \\
\hline $26^{\text {th }} \mathrm{St}$. & 27.02 & 88 & 131 & 24 h Composites & Wastewater Conveyance & $6 / 19 / 2020 ; 7 / 9 / 2020$ \\
\hline $32^{\text {nd }}$ St. & 157.54 & 51 & 391 & 24 h Composites & Wastewater Conveyance & $6 / 19 / 2020 ; 7 / 9 / 2020$ \\
\hline $42^{\text {nd }}$ St. & 13.04 & 100 & 119 & 24 h Composites & Wastewater Conveyance & $6 / 19 / 2020 ; 7 / 8 / 2020$ \\
\hline $48^{\text {th }}$ St. & 593.47 & 75 & 1771 & 24 h Composites & Wastewater Conveyance & $6 / 19 / 2020 ; 7 / 8 / 2020$ \\
\hline $56^{\text {th }}$ St. & 68.49 & 93 & 611 & 24 h Composites & Wastewater Conveyance & $6 / 19 / 2020 ; 7 / 8 / 2020$ \\
\hline $68^{\text {th }}$ St./Schooner & 297.56 & 74 & 1091 & 24 h Composites & Wastewater Conveyance & $6 / 19 / 2020 ; 7 / 8 / 2020$ \\
\hline $70^{\text {th }} \mathrm{St}$. & 6.97 & 100 & 24 & 24 h Composites & Wastewater Conveyance & $6 / 19 / 2020 ; 7 / 8 / 2020$ \\
\hline Bayfront & 330.41 & 67 & 1456 & 24 h Composites & Wastewater Conveyance & $\begin{array}{c}6 / 19 / 2020 ; \\
7 / 8 / 2020 ; 7 / 9 / 2020\end{array}$ \\
\hline Big Creek & 952.72 & 66 & 3569 & 24 h Composites & Wastewater Conveyance & $\begin{array}{c}6 / 19 / 2020 ; \\
7 / 8 / 2020 ; 7 / 9 / 2020\end{array}$ \\
\hline Embarcadero & 34.28 & 33 & 470 & 24 h Composites & Wastewater Conveyance & $6 / 18 / 2020 ; 7 / 8 / 2020$ \\
\hline Hatfield & 196.93 & 12 & 222 & 24 h Composites & Wastewater Conveyance & $6 / 18 / 2020 ; 7 / 9 / 2020$ \\
\hline Minnie St. & 10.68 & 100 & 53 & 24 h Composites & Wastewater Conveyance & $6 / 18 / 2020 ; 7 / 8 / 2020$ \\
\hline Neff & 0.4 & 100 & 12 & 24 h Composites & Wastewater Conveyance & $6 / 19 / 2020 ; 7 / 9 / 2020$ \\
\hline Neolha Point & 4.39 & 100 & 128 & 24 h Composites & Wastewater Conveyance & $6 / 18 / 2020 ; 7 / 9 / 2020$ \\
\hline Northside & 2163.57 & 65 & 9426 & 24 h Composites & Wastewater Conveyance & $\begin{array}{c}6 / 18 / 2020 ; \\
7 / 8 / 2020 ; 7 / 9 / 2020\end{array}$ \\
\hline Nye Beach & 381.78 & 52 & 3023 & 24 h Composites & Wastewater Conveyance & $\begin{array}{c}6 / 18 / 2020 \\
6 / 19 / 2020 ; 7 / 8 / 2020 \\
7 / 9 / 2020\end{array}$ \\
\hline Park St. & 33.22 & 86 & 742 & 24 h Composites & Wastewater Conveyance & $\begin{array}{c}6 / 19 / 2020 ; \\
7 / 8 / 2020 ; 7 / 9 / 2020\end{array}$ \\
\hline $\begin{array}{c}\text { Running Springs/Newport } \\
\text { Bay Estates }\end{array}$ & 11.46 & 100 & 30 & 24 h Composites & Wastewater Conveyance & $6 / 18 / 2020 ; 7 / 9 / 2020$ \\
\hline San-Bay-O & 5.66 & 28 & 18 & 24 h Composites & Wastewater Conveyance & $\begin{array}{c}\text { 6/18/2020; } \\
7 / 8 / 2020 ; 7 / 9 / 2020\end{array}$ \\
\hline Southshore & 40.88 & 100 & 603 & 24 h Composites & Wastewater Conveyance & $6 / 18 / 2020 ; 7 / 9 / 2020$ \\
\hline NW Spring St. & 18.47 & 100 & 402 & 24 h Composites & Wastewater Conveyance & $6 / 19 / 2020 ; 7 / 8 / 2020$ \\
\hline
\end{tabular}




\begin{tabular}{|c|c|c|}
\hline Variant (clade) & B.1.399/NA (G) & B.1/NB (GR) \\
\hline Common SNPs & C241T, C3037T, C14408T, A23403G & C241T, C3037T, C14408T, A23403G \\
\hline Distinctive SNPs & $\begin{array}{l}\text { C2306T*, C11824T*, A18259G*, } \\
\text { G18397A*, A20268G, C28854T, } \\
\text { C28887T }\end{array}$ & $\begin{array}{l}\text { G3995T*, C4809T*, A27373T*, T28318C*, } \\
\text { G28881A, G28882A, G28883C }\end{array}$ \\
\hline $\begin{array}{l}\text { Amino acid } \\
\text { substitutions }\end{array}$ & $\begin{array}{l}\text { ORF1a:L681F, ORF1b:P314L, } \\
\text { ORF1b:I1598V, ORF1b:V1644I, } \\
\text { S:D614G, N:S194L, N:T205I }\end{array}$ & $\begin{array}{l}\text { ORF1a:E1244Z, ORF1a:S1515F, } \\
\text { ORF1b:P314L, S:D614G, ORF6:M58L, } \\
\text { ORF9b:L12S, N:G204R }\end{array}$ \\
\hline $\begin{array}{l}\text { Closest matching } \\
\text { previous } \\
\text { sequences in } \\
\text { GISAID }\end{array}$ & $\begin{array}{l}\text { EPI_ISL_1231275 (Finland 2020-03-20) } \\
\text { EPI_ISL_534859 (England 2020-03-27) } \\
\text { EPI_ISL_534827 (England 2020-03-20) } \\
\text { EPI_ISL-494444 (California 2020-04-16) }\end{array}$ & $\begin{array}{l}\text { EPI_ISL_463510 (Washington 2020-04-29) } \\
\text { EPI_ISL_1015032 (France 2020-03-16) } \\
\text { EPI_ISL_895835 (Czech Repub. 2020-03-16) } \\
\text { EPI_ISL-895820 (Czech Repub. 2020-04-01) }\end{array}$ \\
\hline
\end{tabular}

* unique SNPs used for quantifying variant RNAs

(B) Additional SARS-CoV-2 variants commonly detected in Newport wastewater samples

\begin{tabular}{|c|c|c|c|}
\hline Variant (clade) & B.1.1.158/CC (GR) & B.1.369/EE (GH) & B.1.2/FF (GH) \\
\hline Common SNPs & $\mathrm{C} 241 \Delta, \mathrm{C} 14408 \mathrm{~T}, \mathrm{~A} 23403 \mathrm{G}$ & $\begin{array}{l}\text { C241T, C1059T, } \\
\text { C3037T, } \\
\text { C14408T, } \\
\text { A23403G } \\
\end{array}$ & $\begin{array}{l}\text { C241T, C1059T, C3037T, } \\
\text { C14408T, A23403G }\end{array}$ \\
\hline Distinctive SNPs & $\begin{array}{l}\text { C3042T, A10089G*, G11083T, } \\
\text { C16393T*, C18086T, } \\
\text { C19152T*, T19839C, C25207T, } \\
\text { G28881A, C28807T*, } \\
\text { G28882A, G28883C }\end{array}$ & $\begin{array}{l}\text { C16260T*, } \\
\text { C18695T*', } \\
\text { C19928T*, } \\
\text { C20946T*', } \\
\text { G25563T, } \\
\text { C28821T* }\end{array}$ & $\begin{array}{l}\text { T1927T, C10319T, A18424G*, } \\
\text { C21304T*, A22255T, G25563T, } \\
\text { G25907T*, C26974T, C28472T*, } \\
\text { C28869T }\end{array}$ \\
\hline $\begin{array}{l}\text { Amino acid } \\
\text { substitutions }\end{array}$ & $\begin{array}{l}\text { ORF1a:K3275R, } \\
\text { ORF1a:L3606F, ORF1b:P314L, } \\
\text { ORF1b:P976S, ORF1b:T1540I, } \\
\text { S:D614G, N:G204R }\end{array}$ & $\begin{array}{l}\text { ORF1a:T265I, } \\
\text { ORF1b:P314L, } \\
\text { ORF1b:T1743I, } \\
\text { ORF1b:S2145F, } \\
\text { S:D614G, } \\
\text { ORF3a:Q57H, } \\
\text { N:S183Y }\end{array}$ & $\begin{array}{l}\text { ORF1a:T265I, ORF1a:L3352F, } \\
\text { ORF1b:P314L, ORF1b:N1653D, } \\
\text { ORF1b:R2613C, ORF3a:Q57H, } \\
\text { ORF3a:G172V, ORF8:S24L, } \\
\text { N:P67S, N:P199L }\end{array}$ \\
\hline $\begin{array}{l}\text { Representative } \\
\text { sequences in } \\
\text { GISAID }\end{array}$ & $\begin{array}{l}\text { EPI_ISL_1004180 } \\
\text { EPI_ISL_1004181 } \\
\text { EPI_ISL_1004182 } \\
\text { EPI_ISL_1004183 }\end{array}$ & $\begin{array}{l}\text { EPI_ISL_100419 } \\
0 \\
\text { EPI_ISL_136447 } \\
4\end{array}$ & $\begin{array}{l}\text { EPI_ISL_1017328 } \\
\text { EPI_ISL_1017293 }\end{array}$ \\
\hline
\end{tabular}


Extended Data Table 5. SARS-CoV-2 Variant Relative Abundance. Relative abundances of variants detected in samples from individuals and wastewater across micro-sewersheds during the June 20-21, 2020 prevalence survey.

\begin{tabular}{|c|c|c|c|c|c|c|c|c|c|}
\hline \multirow{3}{*}{ Location } & \multicolumn{4}{|c|}{ Individuals (June 20-21, 2020) } & \multicolumn{5}{|c|}{ Wastewater (June 18 or 19, 2020) } \\
\hline & \multicolumn{2}{|c|}{ Numbers* } & \multicolumn{2}{|c|}{ Fraction } & Fraction & s.e. ${ }^{\dagger}$ & Fraction & s.e. ${ }^{\dagger}$ & $\operatorname{Reps}^{\S}$ \\
\hline & $\mathrm{NA}^{\dagger}$ & $\mathrm{NB}^{\dagger}$ & $\mathrm{NA}^{\dagger}$ & $\mathrm{NB}^{\dagger}$ & \multicolumn{2}{|c|}{$\mathrm{NA}^{\dagger}$} & \multicolumn{2}{|c|}{$\mathrm{NB}^{\dagger}$} & \\
\hline 48th St & 0 & 0 & 0 & 0 & 0.72 & - & 0 & - & 1 \\
\hline 56th St & 0 & 0 & 0 & 0 & 0.94 & - & 0 & - & 1 \\
\hline Bayfront & 0 & 1 & 0 & 1 & 0.92 & 0.01 & 0 & 0 & 2 \\
\hline Big Creek & 1 & 0 & 1 & 0 & 0.98 & 0.01 & 0 & 0 & 2 \\
\hline Northside & 11 & 2 & 0.85 & 0.15 & 0.88 & 0.04 & 0.06 & 0.06 & 3 \\
\hline Nye Beach & 6 & 1 & 0.86 & 0.14 & 0.3 & 0.16 & 0.52 & 0.08 & 3 \\
\hline Park St & 0 & 0 & 0 & 0 & 0.94 & - & 0 & - & 1 \\
\hline San-Bay-O & 0 & 0 & 0 & 0 & 1 & - & 0 & - & 1 \\
\hline Influent & 11 & 2 & 0.85 & 0.15 & 0.7 & 0 & 0.04 & 0.04 & 3 \\
\hline
\end{tabular}

* Numbers of individuals counted for each sewershed include not only those residing within the sewershed itself, but also those residing within upstream sewersheds flowing into the sewershed $\dagger N A=B \cdot 1.399 / N A ; N B=B \cdot 1 / N B$

\$ Standard error calculated on untransformed fractions.

$\S$ Measurements were from a single assay (1), from assays of two independent water samples (2) or from two assays of RNA from one sample and one assay of a second independent sample (3). 


\begin{tabular}{|c|c|}
\hline B.1.399/NA & EPI_ISL_1004213 \\
\hline B.1.399/NA & EPI_ISL_1004214 \\
\hline B.1.399/NA & EPI_ISL_1004215 \\
\hline B.1.399/NA & EPI $^{-}$ISL $^{-} 1004216$ \\
\hline B.1.399/NA & EPI_ISL_1004217 \\
\hline B.1.399/NA & EPI_ISL_1254704* \\
\hline B.1.399/NA & EPI_ISL_1254705 \\
\hline B.1.399/NA & EPI_ISL_1254706 \\
\hline B.1.399/NA & EPI_ISL_1254709 \\
\hline B.1.399/NA & EPI_ISL_1254710 \\
\hline B.1/NB & EPI_ISL_1004178 \\
\hline B.1/NB & EPI_ISL_1254711 \\
\hline B.1/NB & EPI_ISL_1254712 \\
\hline B.1.1.289 & EPI_ISL_1254713* \\
\hline B.1.1.289 & EPI ISL $1254714^{*}$ \\
\hline
\end{tabular}


Extended Data Table 7. Summary of all RT-ddPCR QC Reactions. Improved plate

handling procedures took effect starting with plate 8 (see Supplementary Information).

Only non-detect sample data from plates $<8$ were used. NTC $=$ No-Template Control.

\begin{tabular}{|c|c|c|c|c|c|c|c|}
\hline \multirow[b]{2}{*}{ Control Type } & \multirow[b]{2}{*}{ Target } & \multicolumn{3}{|c|}{$\begin{array}{c}\text { Copies Per Reaction } \\
\text { (all plates) }\end{array}$} & \multirow[b]{2}{*}{$\begin{array}{l}\% \text { Fail }(n, \\
\text { all plates) }\end{array}$} & \multirow[b]{2}{*}{$\begin{array}{l}\% \text { Fail }(n, \\
\text { plates }<8)\end{array}$} & \multirow[b]{2}{*}{$\begin{array}{l}\% \text { Fail }(n, \\
\text { plates } \geq 8\end{array}$} \\
\hline & & Min & Median & $\operatorname{Max}$ & & & \\
\hline $\begin{array}{l}\text { Extraction } \\
\text { Blank }\end{array}$ & N1 & 0.0 & 0.0 & 2.4 & $0.0(158)$ & $0.0(6)$ & $0.0(152)$ \\
\hline $\begin{array}{l}\text { Extraction } \\
\text { Blank }\end{array}$ & N2 & 0.0 & 0.0 & 7.9 & $1.3(158)$ & $16.7(6)$ & $0.7(152)$ \\
\hline $\begin{array}{l}\text { Extraction } \\
\text { Blank }\end{array}$ & $\mathrm{RP}$ & 0.0 & 0.0 & 52.0 & $2.5(158)$ & $33.3(6)$ & $1.3(152)$ \\
\hline Field Blank & N1 & 0.0 & 0.0 & 1.9 & $0.0(49)$ & $0.0(16)$ & $0.0(33)$ \\
\hline Field Blank & $\mathrm{N} 2$ & 0.0 & 0.0 & 6.1 & $2.0(49)$ & $0.0(16)$ & $3.0(33)$ \\
\hline Field Blank & $\mathrm{RP}$ & 0.0 & 0.0 & 27.0 & $4.1(49)$ & $12.5(16)$ & $0.0(33)$ \\
\hline $\begin{array}{l}\text { Negative } \\
\text { Control }\end{array}$ & N1 & 0.0 & 0.0 & 11.9 & $1.2(165)$ & $22.2(9)$ & $0.0(156)$ \\
\hline $\begin{array}{l}\text { Negative } \\
\text { Control }\end{array}$ & $\mathrm{N} 2$ & 0.0 & 0.0 & 12.6 & $3.0(165)$ & $55.6(9)$ & $0.0(156)$ \\
\hline $\begin{array}{l}\text { Negative } \\
\text { Control }\end{array}$ & $\mathrm{RP}$ & 57.2 & 392.1 & 1142.9 & $0.0(165)$ & $0.0(9)$ & $0.0(156)$ \\
\hline NTC & N1 & 0.0 & 0.0 & 17.0 & $3.6(169)$ & $33.3(18)$ & $0.0(151)$ \\
\hline NTC & $\mathrm{N} 2$ & 0.0 & 0.0 & 18.5 & $8.9(169)$ & $77.8(18)$ & $0.7(151)$ \\
\hline NTC & $\mathrm{RP}$ & 0.0 & 0.0 & 91.9 & $8.3(169)$ & $77.8(18)$ & $0.0(151)$ \\
\hline $\begin{array}{l}\text { Positive } \\
\text { Control }\end{array}$ & N1 & 43.2 & 407.8 & 2973.2 & $0.0(164)$ & $0.0(9)$ & $0.0(155)$ \\
\hline $\begin{array}{l}\text { Positive } \\
\text { Control }\end{array}$ & $\mathrm{N} 2$ & 42.1 & 482.4 & 2818.8 & $0.0(164)$ & $0.0(9)$ & $0.0(155)$ \\
\hline $\begin{array}{l}\text { Positive } \\
\text { Control }\end{array}$ & $\mathrm{RP}$ & 86.8 & 399.8 & 1875.6 & $0.0(164)$ & $0.0(9)$ & $0.0(155)$ \\
\hline
\end{tabular}




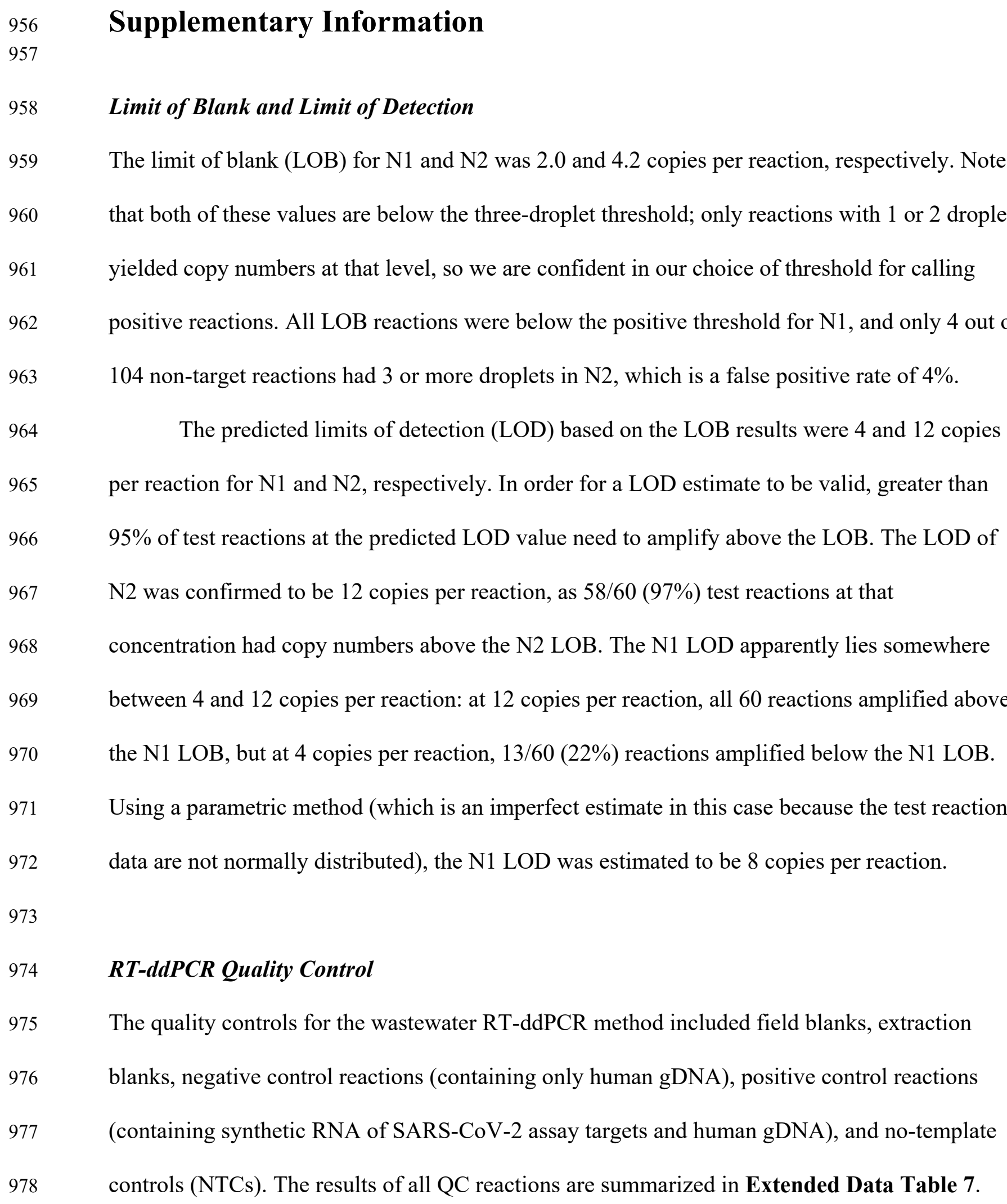

\section{RT-ddPCR Quality Control}

The quality controls for the wastewater RT-ddPCR method included field blanks, extraction blanks, negative control reactions (containing only human gDNA), positive control reactions (containing synthetic RNA of SARS-CoV-2 assay targets and human gDNA), and no-template controls (NTCs). The results of all QC reactions are summarized in Extended Data Table 7. 
Early on in our study we had a cross-contamination issue with the PCR sample plates

resulting from pandemic distancing requirements to prepare the PCR plate in a separate laboratory from the ddPCR system. Initially, we were sealing the prepared PCR plates with an adhesive optical film for transport to the ddPCR laboratory. This seal was then removed upon arrival, and the plate was re-sealed with the Bio-Rad heat sealing foil. We hypothesize that the removal of this adhesive seal caused the cross-contamination of our plates due to aerosolized sample droplets.

Once we stopped the practice of using adhesive seals to transport the plates and instead exclusively used heat sealing foil, the contamination issue was resolved (Extended Data Table 7). We chose to use non-detect sample data from the contaminated plates, while samples with amplification were rerun using archived sample material stored in DNA/RNA Shield (Zymo Research Inc., Irvine, CA) at $80^{\circ} \mathrm{C}$. Only positive detections which passed QA/QC were included in this study.

\section{Bovine coronavirus (BCoV) process recovery control}

BCoV solution was prepared from freeze-dried Calf Guard cattle vaccine (Zoetis, NJ, USA). After rehydrating in $3 \mathrm{~mL}$ of sterile diluent provided by the manufacturer, the BCOV solution was divided into $100 \mu \mathrm{L}$ aliquots and stored at $-20^{\circ} \mathrm{C}$. To use, the $\mathrm{BCoV}$ stock solution aliquot was thawed on ice and vortexed thoroughly; each aliquot was used for a maximum of two freezethaw cycles. BCoV stock solution was spiked into wastewater samples at a ratio of 1/1000 (v/v) before the concentration step. To determine the concentration of BCoV stock solution, $10 \mu \mathrm{L}$ of the stock was spiked in to $390 \mu \mathrm{L}$ PBS and $200 \mu \mathrm{L}$ of that mixture was extracted following the same protocols used for wastewater sample extractions as described in the main text. One 
extraction blank, prepared with PBS, was included on each plate as an RNA extraction contamination control. The extracted RNA was then serially diluted $(1: 10)$ in nuclease-free water for six dilutions and ran in duplicate using a previously established $\mathrm{BCoV}$ assay by following the one-step RT-ddPCR procedure ${ }^{47}$. Stock concentration of BCoV was around 230,000 gc/ $\mu \mathrm{L}$.

Process efficiency (i.e., viral recovery) was calculated by dividing the final quantity of $\mathrm{BCoV}$ measured in wastewater samples to the quantity of $\mathrm{BCoV}$ spiked to each wastewater sample before concentration. The $\mathrm{BCoV}$ recovery was found as $57( \pm 4) \%$ and used to assess SARSCoV-2 RNA loss during sample processing. Non-spiked wastewater samples were also quantified for $\mathrm{BCoV}$ to assess background concentration and $\mathrm{BCoV}$ was not detected in nonspiked wastewater samples, indicating $\mathrm{BCoV}$ is an appropriate viral surrogate.

Viral Concentration Calculation

1016

\section{Supplementary Equation 1. Conversion of Copies per Reaction to Gene Copies per Liter of Wastewater}

